GRADIENT ANALYSIS OF CARBON MONOXIDE AND

METHANE IN POLLUTED AND OTHER

NEARSHORE HABITATS

James Taylor Welch 



\section{Gradient Analysis of Carbon Monoxide and Methane in Polluted and Other Nearshore Habitats}

$$
\text { by }
$$

James Taylor Welch

Lieutenant, United States Navy

B.S.Che., Purdue University, 1966

Submitted in partial fulfillment of the requirements for the degree of

MASTER OF SCIENCE IN OCEANOGRAPHY

from the

NAVAI POSTGRADUATE SCHOOL

March 1973 



\section{ABSTRACT}

A system for the determination of dissolved gases in seawater by gas chromatography was constructed and used to find the concentrations of methane and carbon monoxide in a variety of habitats around the Monterey Peninsula. Methane was shown to have a maximum of $2.8 \times 10^{-4} \mathrm{~m} 1 / 1$ at 50 meters at the open ocean station, with a surface value of $1.1 \times 10^{-4} \mathrm{~m} 1 / 1$. The surface waters at the nearshore stations were almost three times this value. Methane was also shown to be an effective tracer for sewage effluent. The carbon monoxide maximum of $2.1 \times 10^{-4} \mathrm{~m} 1 / 1$ was found at 15 meters which correlated closely with primary productivity (Rowney 1973). The surface value of $0.81 \times 10^{-4} \mathrm{ml} / 1$ was lower than the nearshore values. All stations sampled were found to be highly supersaturated with both gases. This indicates that in this area, the ocean is a major source of both methane and carbon monoxide. 

I. INTRODUCTION

II. EQUIPMENT

A. GAS TRAPPING SYSTEM

1. Sample Transfer

2. Stripping Chamber

3. Trapping Columns - 12

4. Backflush Lines - 12

B. CALIBRATION SYSTEM - 13

C. GAS CHROMATOGRAPH

1. Modifications - 13

D. CATALYST FURNACE - 15

E. RECORDER

III. EXPERIMENTAL METHODS

A. SAMPLE COLLECTION

B. SAMPLE ANALYSIS

IV. RESULTS - 24

A. OPEN OCEAN DEEP STATION

1. Methane - 24

2. Carbon Monoxide - 24

3. Primary Productivity

B. TEMPORAL STUDIES $\ldots \ldots$

C. GRADIENT ANALYSIS - 30

D. TRANSECTS- 42

V. DISCUSSION OF RESULTS - 50

A. PRECISION AND ACCURACY 

B. OPEN OCEAN DEEP STATION

C. TEMPORAL STUDY - 51

D. GRADIENT ANALYSIS - 54

E. TRANSECTS - 55

VI. SUMMARY

VII. RECOMMENDATIONS - 58

APPENDIX A

APPENDIX В

APPENDIX C

APPENDIX D

BIBLIOGRAPHY

INITIAL DISTRIBUTION LIST

FORM DD 1473 



\section{LIST OF TABLES}

TABLE NO.

PAGE NO.

1. Seawater Sampling Stations

2. Methane Concentrations in Monterey Cany on

3. Carbon Monoxide Concentrations in Monterey Canyon -.-.- 28

4. Methane and Carbon Monoxide Concentrations at Del

Monte Beach -.... 32

5. Methane and Carbon Monoxide Concentrations at Point

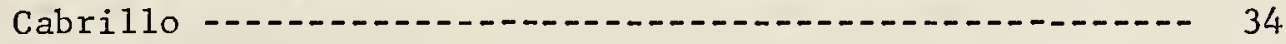

6. Methane and Carbon Monoxide Concentrations at Point

Pinos North -..... 36

7. Methane and Carbon Monoxide Concentrations at Point

Pinos South

8. Methane and Carbon Monoxide Concentrations at Point

Joe -....... 40

9. Methane and Carbon Monoxide Concentrations for the

Transect Along Del Monte Beach _....................... 45

10. Methane and Carbon Monoxide Concentrations for the

Transect from Del Monte Beach to the R-4 Buoy -.....- 47

11. Methane and Carbon Monoxide Concentrations for the

Transect from. Point Cabrillo to the R-4 Buoy -..-...-. 49 

Figure No.

Page No.

1. Schematic diagram of the dissolved gas analysis system -- 11

2. Detailed schematic diagram of the calibration system and traps -..... 14

3. Chart showing location of nearshore stations

4. Chromatogram from a sample run 21

5. Chromatogram from a calibration run

6. Vertical distribution of $\mathrm{CH}_{4}$ at the Deep Ocean Station in Monterey Canyon -... 25

7. Vertical distribution of $\mathrm{CO}$ at the Deep Ocean Station in Monterey Canyon -... 27

8. Vertical distribution of Primary Productivity in the upper 50 meters of the Deep Ocean Station in Monterey Canyon -... 29

9. $\mathrm{CH}_{4}$ and $\mathrm{CO}$ concentrations in the surface waters at Del Monte Beach -...- 31

10. $\mathrm{CH}_{4}$ and $\mathrm{CO}$ concentrations in the surface waters at Point Cabrillo

11. $\mathrm{CH}_{4}$ and $\mathrm{CO}$ concentrations in the surface waters at Point Pinos North

12. $\mathrm{CH}_{4}$ and $\mathrm{CO}$ concentrations in the surface waters at Point Pinos South - 37

13. $\mathrm{CH}_{4}$ and $\mathrm{CO}$ concentrations in the surface waters at Point Joe -

14. Surface temperature

15. $\mathrm{CH}_{4}$ and $\mathrm{CO}$ gradients between the five nearshore stations- 43

16. $\mathrm{CH}_{4}$ and $\mathrm{CO}$ concentrations for a transect along Del Monte Beach - 44

17. $\mathrm{CH}_{4}$ and $\mathrm{CO}$ concentrations for transects from Del Monte Beach to the R-4 Bell Buoy - 46 

18. $\mathrm{CH}_{4}$ and $\mathrm{CO}$ concentrations for a transect from Point Cabrillo to the R-4 Bell Buoy - 48

19. Plot of $\mathrm{CH}_{4}$ versus $\mathrm{CO}$ in the Deep Ocean Station in the Monterey Canyon. Numbers indicate depth in meters - 52 



\section{ACKNOWLEDGEMENTS}

The author wishes to express his appreciation to:

Dr. Eugene D. Traganza, for his guidance and inspiration in all phases of this project, and his close attention to detail in the preparation of this thesis.

Dr. Charles F. Rowell, for his advice, assistance and critical review of this work.

Dr. Eugene C. Haderlie for his critical review of the manuscript.

Dr. John W. Swinnerton and Mr. Robert A. Lamontagne of the Naval Research Laboratory for their technical advice and support throughout this project.

Mr. Kenneth J. Graham, Department of Research Administration, Robert Sanders of the Department of Physics and Chemistry, Roy Edwards of the Department of Mechanical Engineering, and Bill Penpraze of the Department of Electrical Engineering, for their help in the construction and trouble-shooting of the system.

The Naval Postgraduate School boat crew and Lt. John V. Rowney for their enthusiastic assistance in sample collection under often adverse weather conditions.

A special thanks to Mr. Robert Scheile of the Research Department for his expert technical assistance in the design and construction of the system. 



\section{INTRODUCTION}

The ocean has been shown to be supersaturated with carbon monoxide (Swinnerton, Linnenbom, and Lamontagne, 1970). The sources for this gas may be plants (Chapman and Tocher, 1966; Delwiche, 1970; Loewus and Delwiche, 1963), animals (Pickwell and Barham, 1964; Pickwell, 1970; Barham, 1963; Wittenberg, 1960), and microorganisms (Junge, et. a1., 1971). These results led to the hypothesis that carbon monoxide production might be related to primary productivity. The highly productive waters of Monterey Bay were thought to be an excellent location to test this hypothesis.

Methane has also been reported as being present in surface waters (Swinnerton, Linnenbom, and Cheek, 1969). Since this gas is a product of anaerobic decomposition of organic matter it was felt that it might be useful as a pollution tracer from sewage outfalls. Again, Monterey Bay provides an excellent environment for these studies.

In order to measure these gases, the highly sensitive methods of gas chromatography were used. The gas chromatograph has long been one of the analytical chemist's most useful instruments. It was not until 1962 that a practical system for oceanographic analyses was developed (Swinnerton, Linnenbom, and Cheek, 1962). Today, the shipboard determination of dissolved gases by gas chromatography is one of the most valuable methods available to the chemical oceanographer. 



\section{EQUIPMENT}

The system used was essentially that described by Swinnerton, Linnenbom, and Cheek (1968). A calibration system was added and minor modifications were made in the sample transfer system. The entire system is shown in Figure 1.

\section{A. GAS TRAPPING SYSTEM}

The separation is accomplished in four major steps. They are sample transfer, stripping, trapping, and backflushing.

\section{Sample Transfer}

A helium line is connected to the side port of a Swagelok heat exchanger " $\mathrm{T}$ ". A standard taper joint is attached to the bottom of this " $T$ " that fits into the filled sample bottle. A $1 / 8$ " stainless steel tube runs from the bottom of the sample bottle through the heat exchanger " $T$ " and is connected to the bottom of the stripping chamber.

Transfer of the sample is accomplished by displacement with helium. The helium flow is controlled by a micrometer valve. The helium forces the water sample through the stainless steel tube into the stripping chamber. A toggle valve is located in the helium line to release the pressure in the sample bottle after transfer.

\section{Stripping Chamber}

The stripping chamber is a glass tube $65 \mathrm{~mm}$. in diameter and $45 \mathrm{~cm}$. tall. It is fitted with a coarse fritted disc at the bottom and a $10 \mathrm{~cm}$. neck, $2 \mathrm{~cm}$. in diameter, at the top. "Purge helium" is introduced just below the fritted disc. It is controlled by a Teflon stopcock and its flow rate is held at $70 \mathrm{ml} / \mathrm{min}$ by a Brooks flow control valve.

Just above the fritted disc is the sample inlet. It is connected 



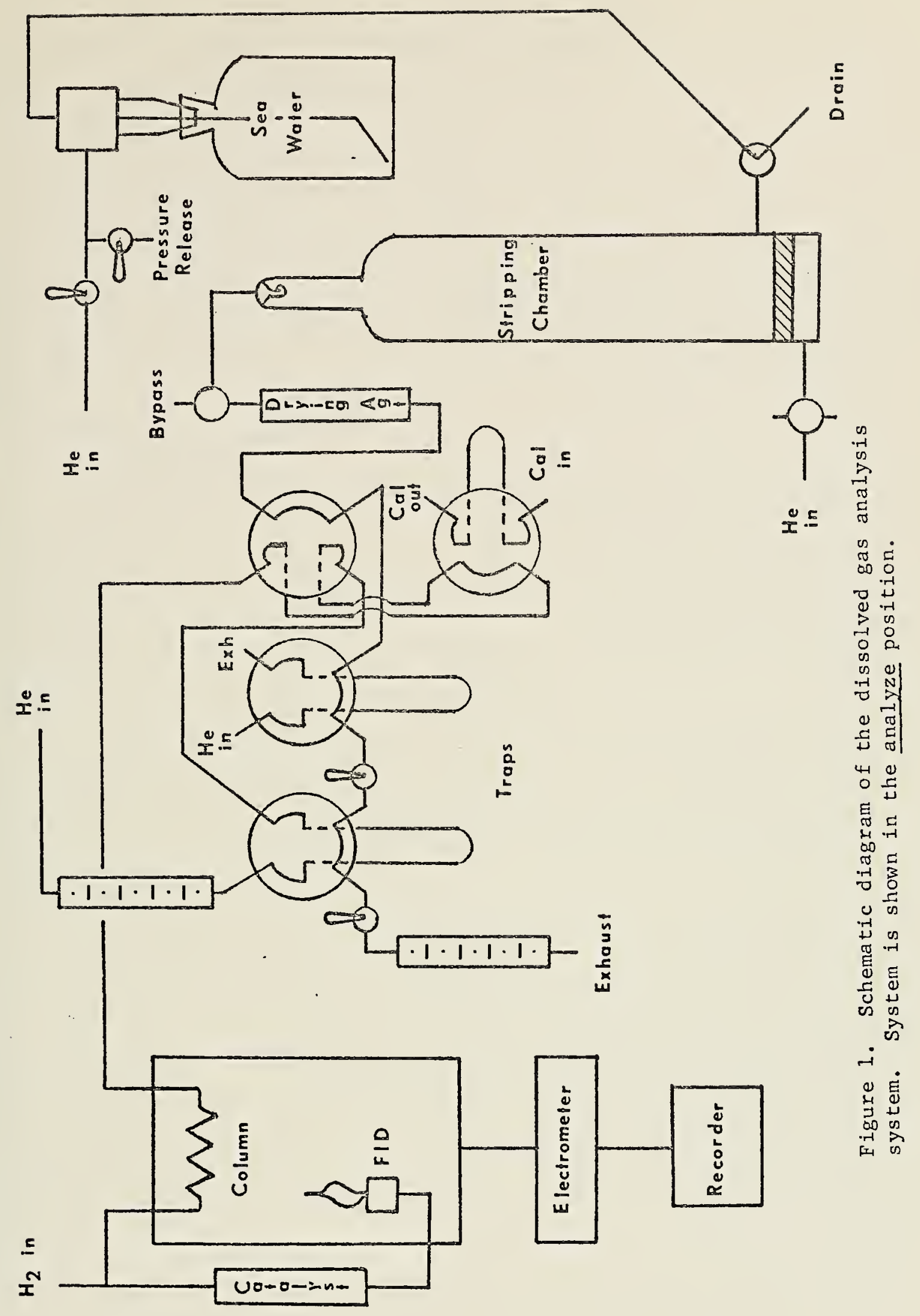



to one port of a Y-type stopcock. This stopcock allows the operator to purge the line prior to sample transfer, transfer the sample, and later, drain the chamber.

The neck of the chamber is fitted with a ground glass joint. This provides an opening for cleaning and a place to insert the magnetic stirring bar. At the top of the neck is a modified Kjeldahl tip. This breaks any bubbles and thus keeps water from being carried into the rest of the system.

\section{Trapping Columns}

The traps were constructed of $3 / 16^{\prime \prime}$ stainless steel tubing. The first trap was packed with ten inches of $60 / 80$ mesh activated alumina and the second with a mixture containing $\frac{1}{4}$ activated charcoal and $3 / 430 / 60$ mesh 5A molecular sieve. They were connected across the sample loop ports of Perkin-Elmer gas sampling valves (See Figure 2).

Toggle valves were placed on either side of the activated charcoal/ molecular sieve trap. These allowed the trap to be isolated while holding a sample and thus precluded any gas leakage prior to analysis.

\section{Backflush Lines}

A constant flow of helium had to be maintained across the column in the chromatograph. This was accomplished in that in the trap position, the carrier gas was passing through the gas sampling valve for the activated charcoal/molecular sieve trap to the chromatograph. In the analyze position, the carrier gas backflushed the trapped sample gases to the chromatograph. The flow rate was maintained at $30 \mathrm{ml} / \mathrm{min}$ by a Brooks flow control valve.

After the analysis was complete, the activated alumina trap was backflushed with line helium to remove trapped gases. Since this trap was 

not analyzed, a cap was placed on the exhaust port when the valve was in the trap position, in order to conserve helium and maintain pressure for stripping. It also kept water from backing up into the system.

\section{B. CALIBRATION SYSTEM}

In order to have consistent calibrations, a gas sampling valve with a $1 \mathrm{ml}$. sample loop was incorporated into the system. This enabled a known gas mixture to be introduced into the trapping system or directly into the chromatograph. A diagram showing the calibration system is shown in Figure 2 .

\section{GAS CHROMATOGRAPH}

A Varian Aerograph Model 600C gas chromatograph was obtained on loan from the Department of Physics and Chemistry. It was equipped with a flame ionization detector (FID), a tube-type electrometer, and a Model 328 isothermal temperature controller.

\section{Modifications}

The original column was replaced with a four foot, 3/16", stainless steel column packed with $30 / 60$ mesh $5 \mathrm{~A}$ molecular sieve. Upon conditioning (heating for two hours at $150{ }^{\circ} \mathrm{C}$ in a helium atmosphere), this column provided adequate separation of carbon monoxide and methane.

The normal carrier-gas port and injection port on the gas chromatograph were bypassed since the already mixed unknown and carrier gas were entering from the traps, i.e., there was a direct connection of the line from the activated charcoal/molecular sieve trap to the column.

The hydrogen port was also sealed since the hydrogen was introduced prior to a catalyst tube. 



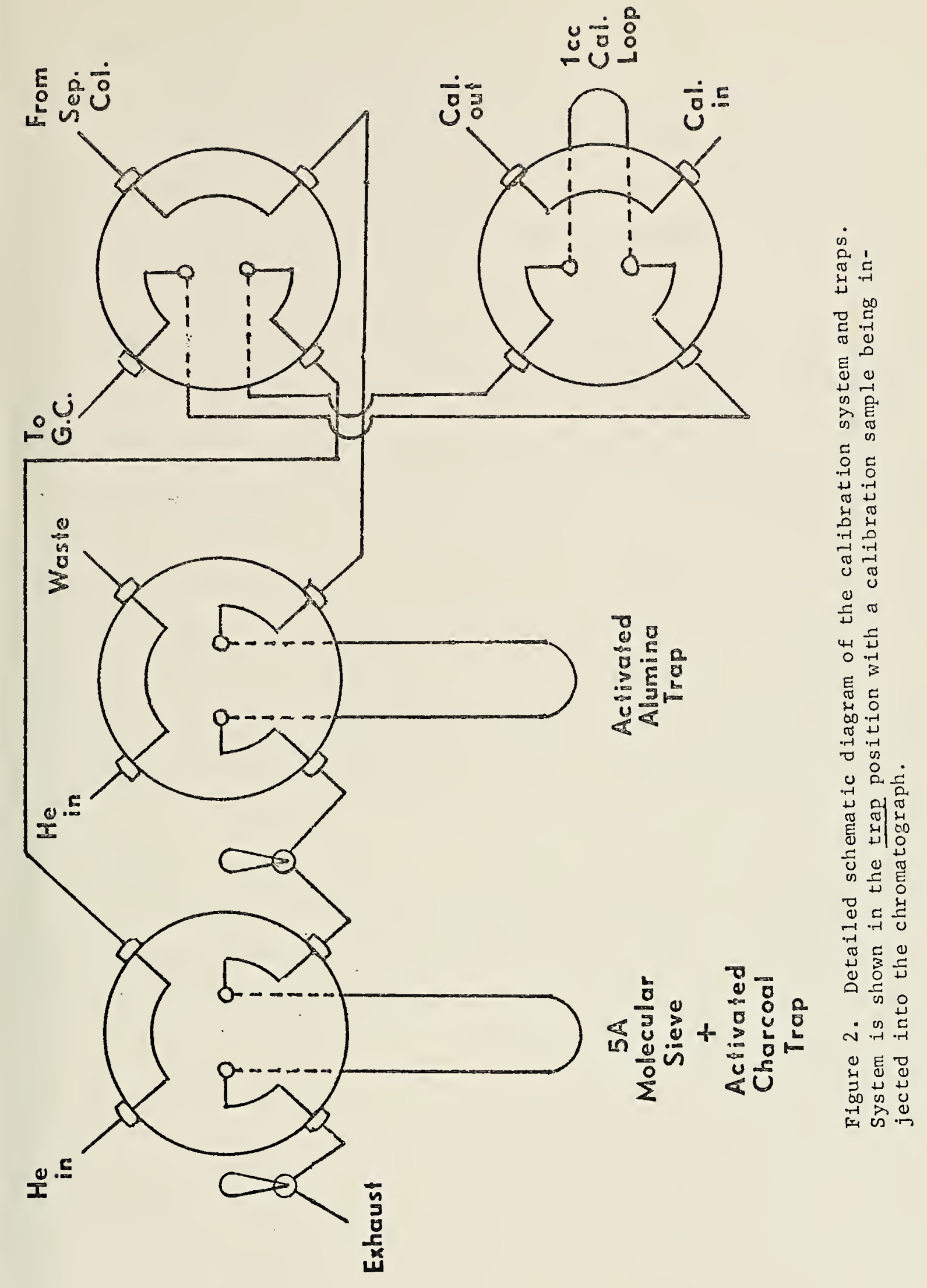





\section{CATALYST FURNACE}

The flame ionization detector is not sensitive to carbon monoxide. Therefore, the carbon monoxide must be converted to methane prior to analysis. This is accomplished by passing the carbon monoxide over a heated nickel catalyst in the presence of hydrogen (Porter and Vollman, 1962).

The catalyst furnace was placed between the analytical column and the detector. It consisted of a $10 \mathrm{~cm}$., $\frac{11}{4} "$, stainless steel tube in which the catalyst was placed. An aluminum block $7.5 \mathrm{~cm}$. long and $2.5 \mathrm{~cm}$. in diameter was placed around this tube as a heat sink. This assembly was placed flush inside a threaded quartz tube which was wound with a Nichrome wire heater. To prevent fire and provide additional insulation, the heater was placed in a Transite box which was mounted on the side of the chromatograph. The temperature was monitored with a five ohm iron-constantan thermocouple attached to the auxillary terminal of the temperature controller. Temperature control was regulated with a Variac controller.

\section{E. RECORDER}

A Varian Mode1 G-14 strip chart recorder was used to record the output of the electrometer. It was set for $1 \mathrm{mv}$. full scale deflection and run at a chart speed of 1 in./min. 



\section{EXPERIMENTAL METHODS}

\section{A. SAMPLE COLLECTION}

Five nearshore stations were taken in kelp beds around the Monterey Peninsula as described in Table 1 and Figure 3. The stations varied from a relatively calm area at Del Monte Beach to areas of extreme turbulence on the exposed coast at Point Pinos and Point Joe. These stations were occupied periodically from 31 October 1972 to 15 December 1972.

Sampling in the nearshore areas was done from a forty foot boat. In order to minimize contamination from the exhaust, the boat was allowed to drift to a stop in the kelp beds prior to sampling. Samples were taken in a Van Dorn type bottle that was rigged with hand lines for lowering and tripping.

Samples were collected in $500 \mathrm{ml}$. reagent bottles by filling from the bottom with a surgical rubber tube. The bottles were then sealed with a standard taper ground glass stopper. This reduced the possibility of air contamination and outgassing from the sample. If the samples were to be stored before analysị, a small amount of sodium azide $\left(\mathrm{NaN}_{3}\right)$ was added to kill any organisms that might alter the dissolved gas concentrations.

In order to have open ocean values to compare with those found in the nearshore habitats, a deep station was taken in the Monterey Canyon aboard R/V Acania (see Table 1). Samples were taken at depths of 0,5 , $15,30,50,75,100,200,500,700$, and 1000 meters using standard Nansen bottles. In addition, a cast was made at $0,5,12,18$, and 45 meters for determination of primary productivity (see Rowney, 1973). 



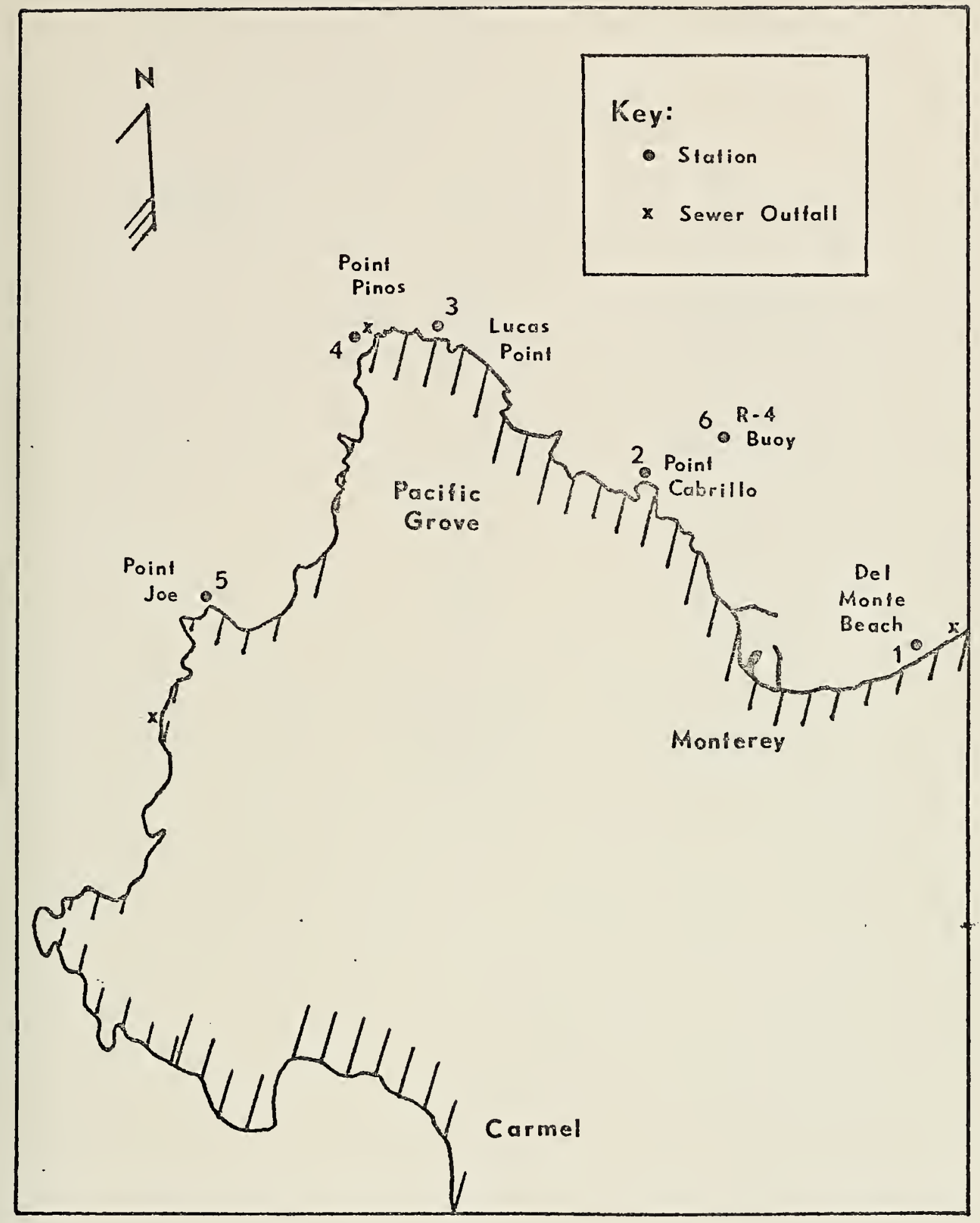

Figure 3. Chart showing location of nearshore stations. 

Table 1

Seawater Sampling Stations

Station

Number

Name

$\underline{\text { Positions }}$

1

De1 Monte

Beach

$36^{\circ} 36.3^{\prime} \mathrm{N}$

$121^{\circ} 52.4^{\prime} \mathrm{W}$

2

Point

$36^{\circ} 37.4^{\prime} \mathrm{N}$

Cabri11o

$121^{\circ} 54.1^{\prime} \mathrm{W}$

3

Point Pinos

$36^{\circ} 38.3^{\prime} \mathrm{N}$

North

$121^{\circ} 55.4^{\prime} \mathrm{W}$

4

Point Pinos

$36^{\circ} 38.3^{\prime} \mathrm{N}$

South

$121^{\circ} 56.3^{\prime} \mathrm{W}$

5

Point

$36^{\circ} 36.8^{\prime} \mathrm{N}$

Joe

$121^{\circ} 57.3^{\prime} \mathrm{W}$

6

$\mathrm{R}-4$

Be11 Buoy

$36^{\circ} 37.5^{\prime} \mathrm{N}$

$121^{\circ} 54.3^{\prime} \mathrm{W}$

7

Monterey

Canyon

$36^{\circ} 44.3^{\prime} \mathrm{N}$

$122^{\circ} 07.2^{\prime} \mathrm{W}$ 

Transects were taken across Del Monte Beach, from Del Monte Beach to the R-4 buoy, and from Point Cabrillo to the $\mathrm{R}-4$ buoy. These were taken to determine any gradients present.

\section{B. SAMPLE ANALYSIS ${ }^{1}$}

The sample bottle was connected to the system by a ground glass joint. Helium was introduced above the sample forcing the water through a stainless steel tube to the drain valve. The first few milliliters were discarded to ensure flushing of the transfer line. The stripping chamber, which had been previously drained to the $500 \mathrm{ml}$. mark, was then filled to the zero mark. This method of transfer minimized contact with the atmosphere and thus reduced the chance of contamination.

"Purge helium" was introduced below the fritted disc and allowed to bubble through the sample for twelve minutes. A magnetic stirring bar in the chamber increased the residence time of the bubbles in the sample. After twelve minutes, no measurable amounts of carbon monoxide or methane were left in the sample and as prior tests showed, no leakage from the cold traps had occurred. Before reaching the traps, the gas passed through a magnesium perchlorate drying agent to remove any water vapor.

Trapping of the gases took place on two series-connected cold traps. They were both maintained at $-77^{\circ} \mathrm{C}$ with an acetone-dry ice bath, in a Dewar flask. The first trap was an activated alumina column which removed any hydrocarbons higher than methane as well as carbon dioxide. The second, a mixture of $1 / 4$ activated charcoal and $3 / 4$ molecular sieve, removed carbon monoxide, methane, and air. In the twelve minute purging time, most

A complete, step-by-step, analysis check list is included in Appendix A. 

of the air was bled off the trap and only a small amount of residual oxygen remained. This proved to be no problem since the analytical column in the gas chromatograph provided sufficient separation of these gases. After the twelve minutes of purging time, isolation valves on either side of the activated charcoal/molecular sieve trap were closed. The acetone-dry ice bath was removed and replaced with one of boiling water. The trap was now backflushed into the analytical column in the gas chromatograph. The activated alumina trap was backflushed to the atmosphere since its contents were not of importance to this experiment.

Retention times for a column temperature of $48^{\circ} \mathrm{C}$ and a flow rate of $30 \mathrm{ml} / \mathrm{min}$ were: air, $1.5 \mathrm{~min}$; methane, $3.0 \mathrm{~min}$; carbon monoxide, 4.25 min. Analysis was complete seven minutes after injection of the sample into the gas chromatograph.

To ensure complete conversion of carbon monoxide to methane, the catalyst furnace was held between $300-320^{\circ} \mathrm{C}$. This also reduced tailing on the carbon monoxide peak.

Figure 4 shows a chromatogram from a sample analysis. The concentration of each gas is proportional to the area under its respective peak. In order for these areas to be meaningful, a method of calibration was needed.

To accomplish this, a calibration gas is used. A calibrated gas mixture of $70.3 \mathrm{ppm}$ methane and $71.1 \mathrm{ppm}$ carbon monoxide in air was obtained from the Naval Research Laboratory, Washington D.C. Preliminary work showed no measurable difference in the results when the gas was introduced into the traps or directly into the gas chromatograph, therefore direct injection was used to conserve time.

Figure 5 shows the results of a calibration run. Now, the response of the system to a known concentration of gas was known and the unknown 



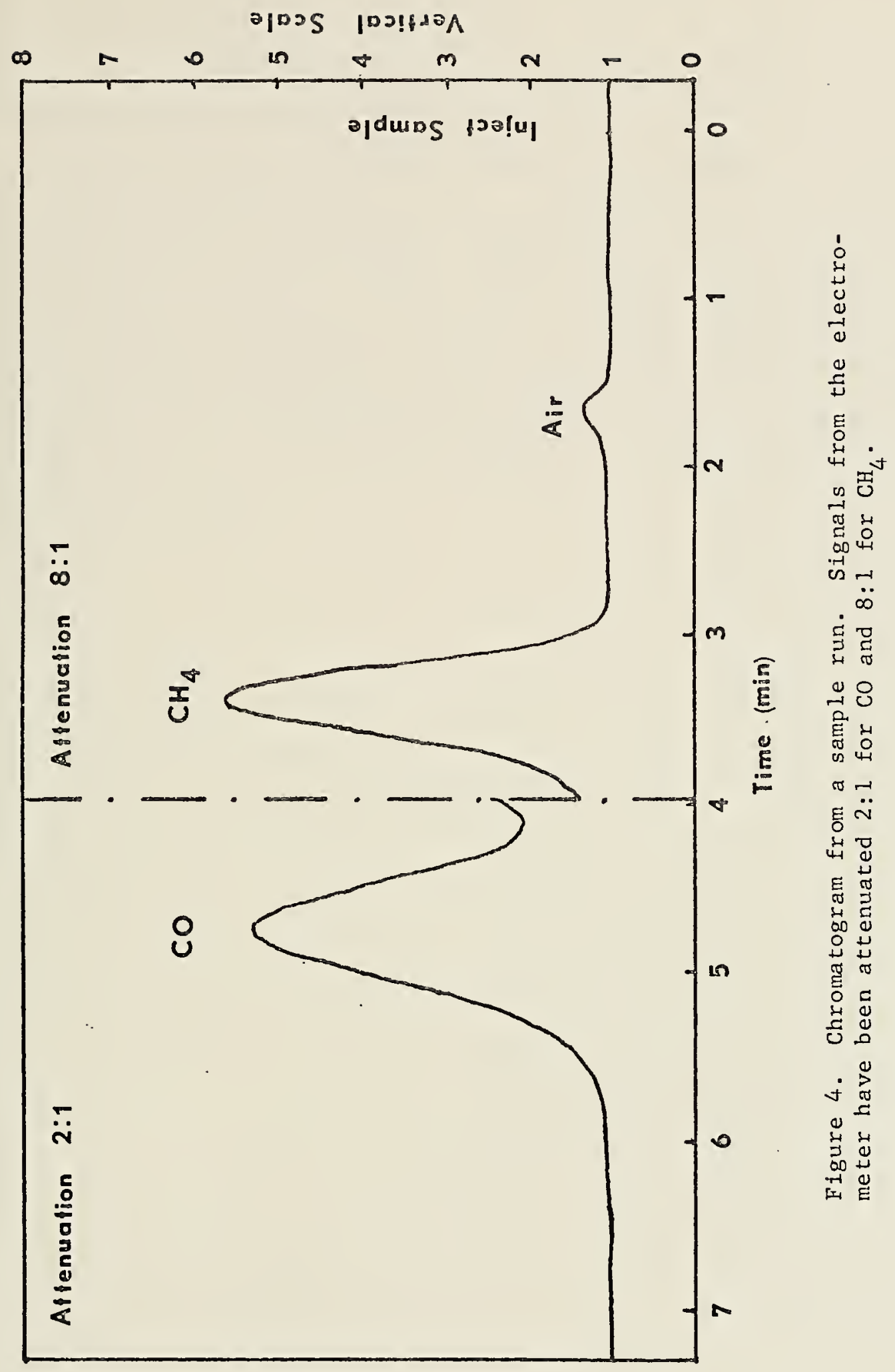



concentrations could be determined by comparing areas. Calibrations were run periodically along with the samples. In addition to calibrating the system, these calibration checks were also used to determine if the catalytic conversion of carbon monoxide to methane was complete.

After the sample was run, the area under each peak was determined in the following manner. The height of the peak and the width at half height were measured with a set of dial calipers. These values were multiplied together to get the raw area; a range and attenuation factor from the electrometer setting was applied to get the effective area. These calculations were carried out on the IBM $360 / 67$ computer. A copy of the program is included in Appendix $C$. 



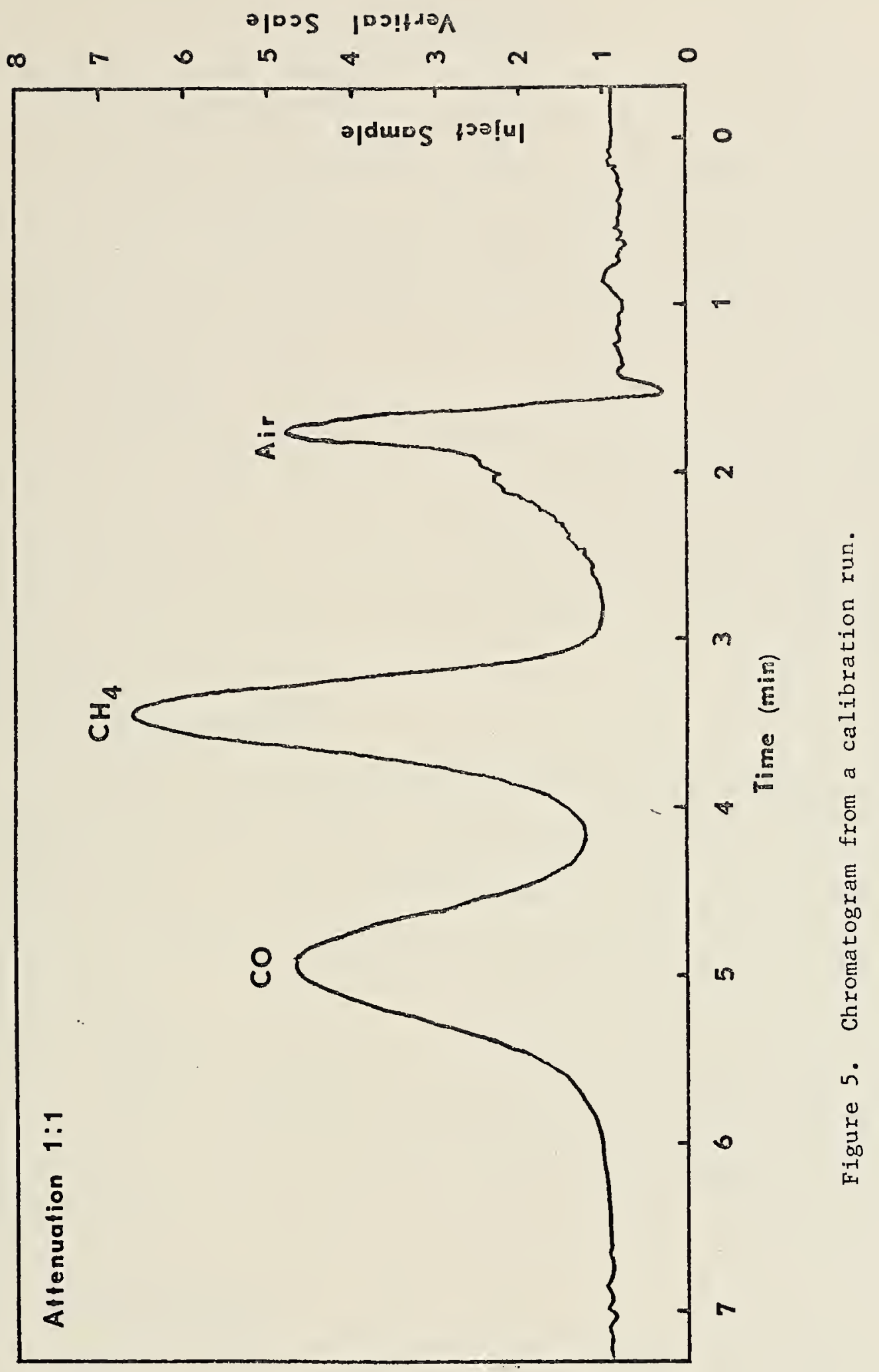





\section{RESULTS}

\section{A. OPEN OCEAN DEEP STATION}

Station seven (Table 1) was located on the axis of the Monterey Submarine Canyon in 1375 meters of water. An eleven bottle cast to 1000 meters was taken. The profiles from this cast are shown in Figures 6 and 7 and tabulated in Tables 2 and 3.

\section{Methane}

The methane profile (Figure 6 and Table 2) shows a surface concentration of $1.1 \times 10^{-4} \mathrm{~m} 1 / 1$. This value increases with depth to 50 meters. From 50 to 100 meters it decreases slightly and then more rapidly to 200 meters. It then decreases linearly with depth at a rate of $0.125 \times 10^{-4}$ $\mathrm{ml} / 1 / 100 \mathrm{~m}$ to 1000 meters.

\section{Carbon Monoxide}

Figure 7 and Table 3 shows a carbon monoxide concentration of $0.81 \times 10^{-4} \mathrm{ml} / 1$ at the surface. This value increases sharply to almost $2 \times 10^{-4} \mathrm{ml} / 1$ at 15 meters and then decreases to near surface values at 100 meters. From 100 to. 1000 meters, the concentration decreases to only trace amounts.

\section{Primary Productivity}

Primary productivity measurements made by Rowney (1973) at the same station are shown in Figure 8. Note the relatively high values in the upper 12 meters.

\section{B. TEMPORAL STUDIES}

A temporal study of carbon monoxide and methane was conducted in each of the five nearshore habitats. The plots of concentration versus time 



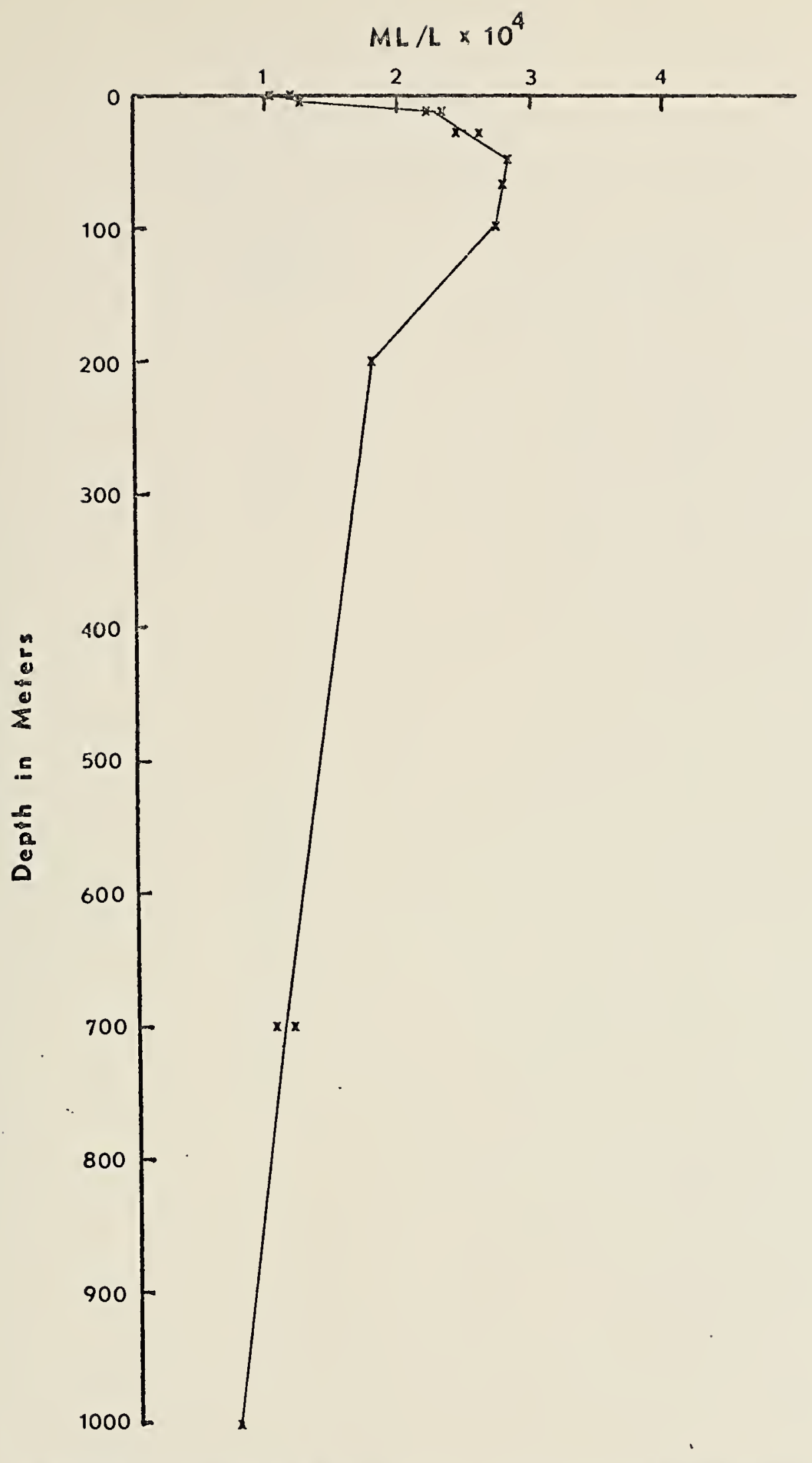

Figure 6. Vertical distribution of $\mathrm{CH}_{4}$ at the Deep Ocean Station in Monterey Canyon. 

Table 2

Methane Concentrations in Monterey Canyon

\begin{tabular}{cc}
$\begin{array}{c}\text { Depth } \\
\text { (meters) }\end{array}$ & $\begin{array}{c}\text { Methane Concentration } \\
(\mathrm{m} 1 / 1)\end{array}$ \\
\cline { 2 - 2 } 0 & $1.013 \times 10^{-4}$ \\
0 & $1.184 \times 10^{-4}$ \\
5 & $1.252 \times 10^{-4}$ \\
15 & $2.342 \times 10^{-4}$ \\
15 & $2.205 \times 10^{-4}$ \\
30 & $2.433 \times 10^{-4}$ \\
30 & $2.632 \times 10^{-4}$ \\
50 & $2.847 \times 10^{-4}$ \\
75 & $2.783 \times 10^{-4}$ \\
100 & $2.752 \times 10^{-4}$ \\
200 & $1.797 \times 10^{-4}$ \\
200 & $1.759 \times 10^{-4}$ \\
700 & $1.037 \times 10^{-4}$ \\
1000 & $0.751 \times 10^{-4}$
\end{tabular}





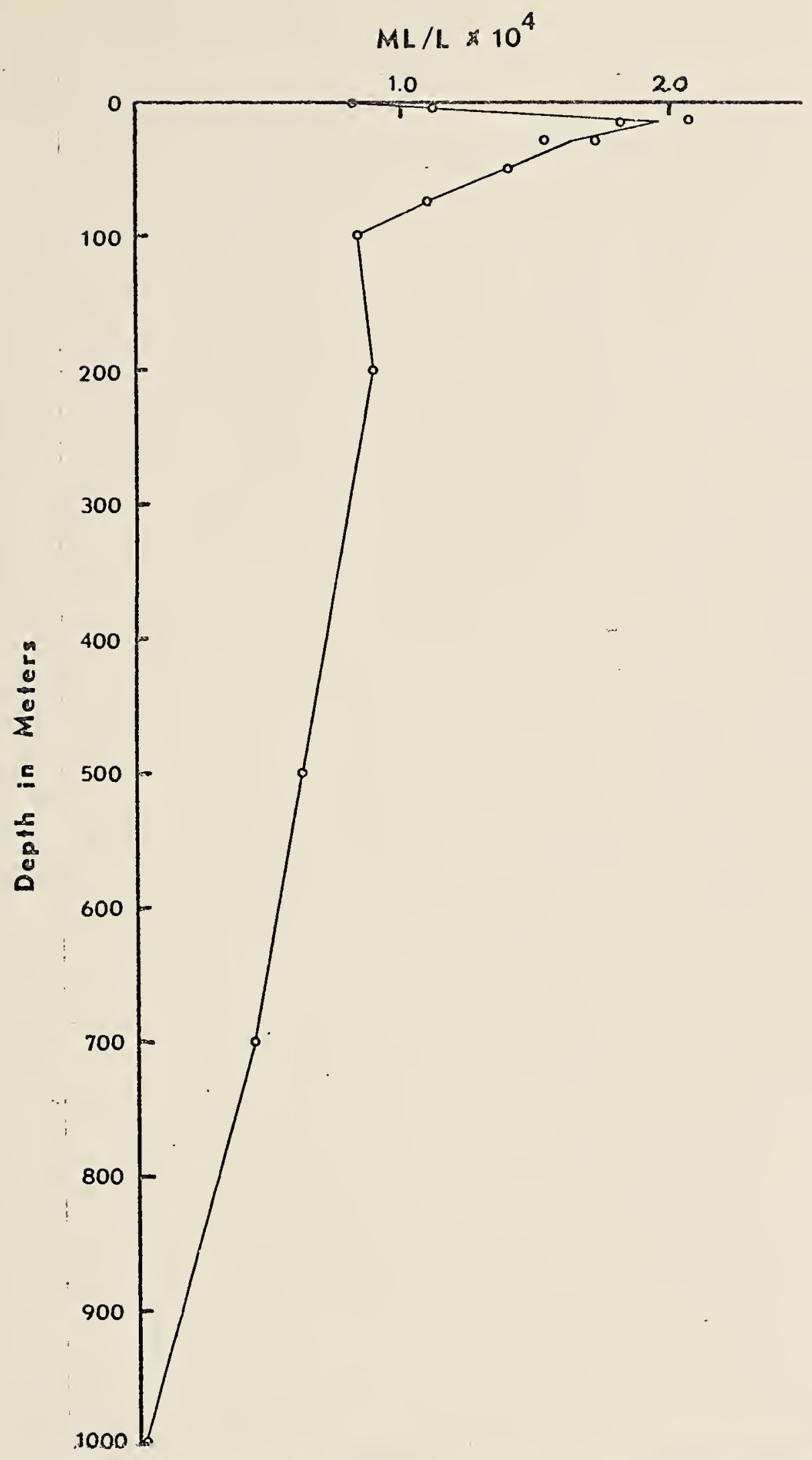

Figure 7. Vertical distribution of $\mathrm{CO}$, at the Deep Ocean Station in Monterey Canyon. 

Table 3

Carbon Monoxide Concentrations in Monterey Canyon

\begin{tabular}{|c|c|c|}
\hline $\begin{array}{c}\text { Depth } \\
\text { (meters) }\end{array}$ & Carbon & $\begin{array}{c}\text { Monoxide Concentration } \\
(\mathrm{m} 1 / 1)\end{array}$ \\
\hline 0 & & $0.793 \times 10^{-4}$ \\
\hline 0 & & $0.836 \times 10^{-4}$ \\
\hline 5 & & $1.230 \times 10^{-4}$ \\
\hline 15 & & $2.144 \times 10^{-4}$ \\
\hline 15 & & $1.818 \times 10^{-4}$ \\
\hline 30 & & $1.522 \times 10^{-4}$ \\
\hline 30 & & $1.729 \times 10^{-4}$ \\
\hline 50 & & $1.391 \times 10^{-4}$ \\
\hline 75 & & $1.086 \times 10^{-4}$ \\
\hline 100 & & $0.759 \times 10^{-4}$ \\
\hline 200 & & $0.836 \times 10^{-4}$ \\
\hline 200 & & $0.859 \times 10^{-4}$ \\
\hline 500 & & $0.619 \times 10^{-4}$ \\
\hline 700 & & $0.436 \times 10^{-4}$ \\
\hline 1000 & & trace \\
\hline
\end{tabular}





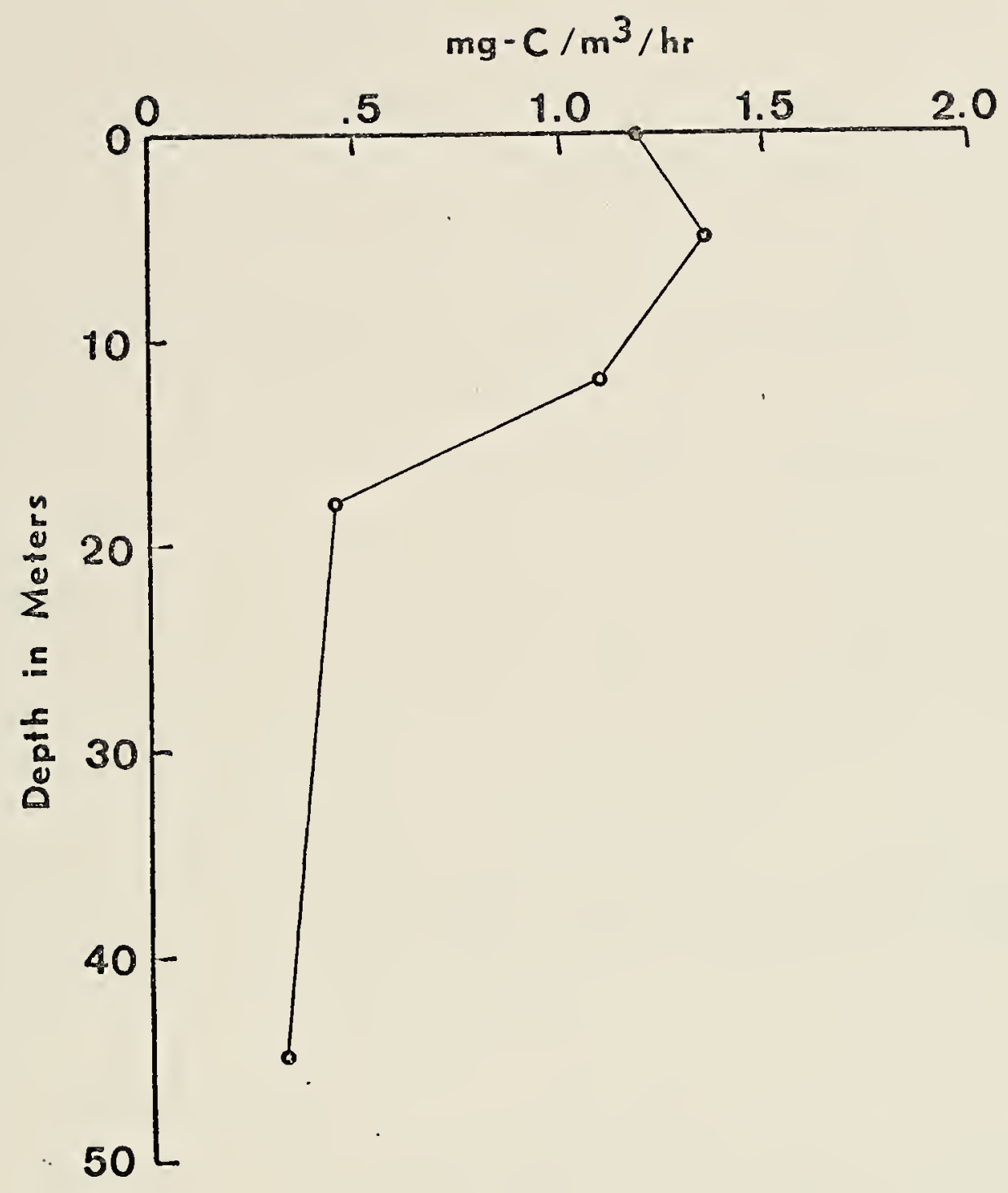

Figure 8. Vertical distribution of Primary Productivity in the upper 50 meters of the Deep Ocean Station in Monterey Canyon (from Rowney, 1973). 

are found in Figures 9 through 13 and are tabulated in Tables 4 through 8.

Environmental conditions were as follows. The period prior to 31 October 1972 had been clear for several weeks. During the periods 4-17 November and 3-8 December 1972, overcast skies with heavy rains were predominant. The rest of the time, clear skies prevailed. Heavy swell accompanied the periods of rain. This made it impossible to sample stations 3,4 , and 5 during these periods, since it was too rough for the forty foot boat. The surface temperature (Figure 14) decreased from $15^{\circ} \mathrm{C}$ at the start of the study to $10^{\circ} \mathrm{C}$ at its conclusion.

A11 five stations showed high methane concentrations on the first day. These values dropped sharply after the onset of the first storm. Following this storm, the concentrations began to rise, but were again decreased after the second storm. Del Monte Beach showed another increase after this second storm that was not noted at the other stations.

Carbon monoxide did not seem to be affected by the rains as much as methane. It was uniformly low at the start of the study with a general increase throughout the time period. Again, Del Monte Beach showed more variability than the other stations.

\section{GRADIENT ANALYSIS}

The average of all measurements at each nearshore station was computed and plotted (Figure 15). This provided a gradient analysis for comparison with primary productivity, chlorophy11 and nutrient analyses (Rowney 1973).

The methane gradient decreased from Del Monte Beach to Point Cabrillo. It then reversed and showed an increase to the highest value at Point Joe.

Carbon monoxide showed a different pattern. It alternated between decreasing and increasing gradients with a slight overall trend towards higher concentrations at Point Joe. 



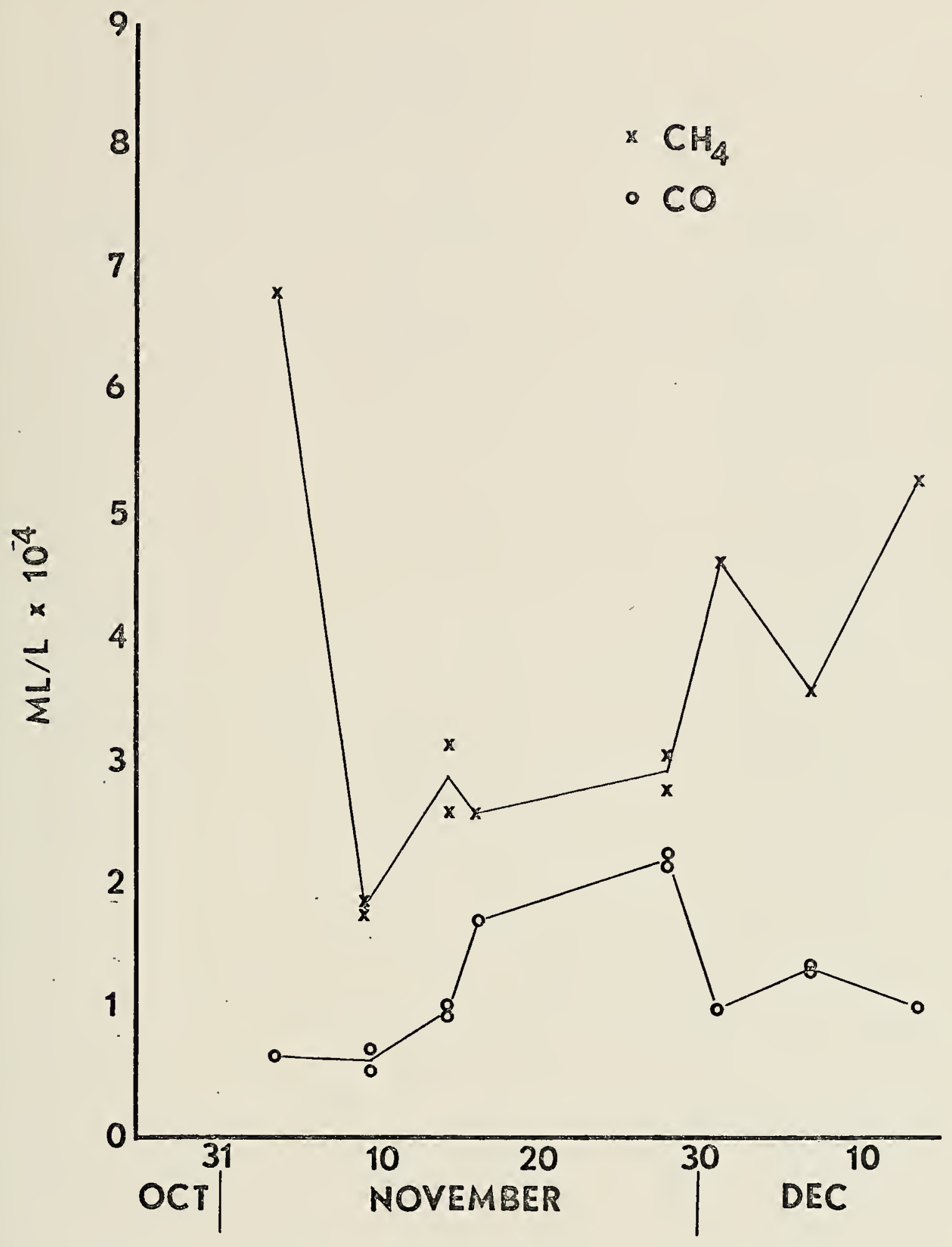

Figure 9. $\mathrm{CH}_{4}$ and $\mathrm{CO}$ concentrations in the surface waters at Del Monte Beach. 

Table 4

Methane and Carbon Monoxide

Concentrations at De1 Monte Beach

Date

$11-03-72$

$11-09-72$

$11-09-72$

$11-14-72$

$11-14-72$

$11-16-72$

$11-28-72$

$11-28-72$

$12-01-72$

$12-07-72$

$12-07-72$

$12-14-72$

$12-14-72$
Methane

(m1/1)

$6.829 \times 10^{-4}$

$1.842 \times 10^{-4}$

$1.959 \times 10^{-4}$

$2.648 \times 10^{-4}$

$3.187 \times 10^{-4}$

$2.631 \times 10^{-4}$

$3.102 \times 10^{-4}$

$2.837 \times 10^{-4}$

$4.682 \times 10^{-4}$

$3.669 \times 10^{-4}$

$3.547 \times 10^{-4}$

$5.358 \times 10^{-4}$

$5.277 \times 10^{-4}$
Carbon Monoxide (m1/1)

$0.663 \times 10^{-4}$

$0.546 \times 10^{-4}$

$0.735 \times 10^{-4}$

$0.990 \times 10^{-4}$

$1.088 \times 10^{-4}$

$1.763 \times 10^{-4}$

$2.208 \times 10^{-4}$

$2.318 \times 10^{-4}$

$1.039 \times 10^{-4}$

$1.408 \times 10^{-4}$

$1.345 \times 10^{-4}$

$1.046 \times 10^{-4}$

$1.082 \times 10^{-4}$ 



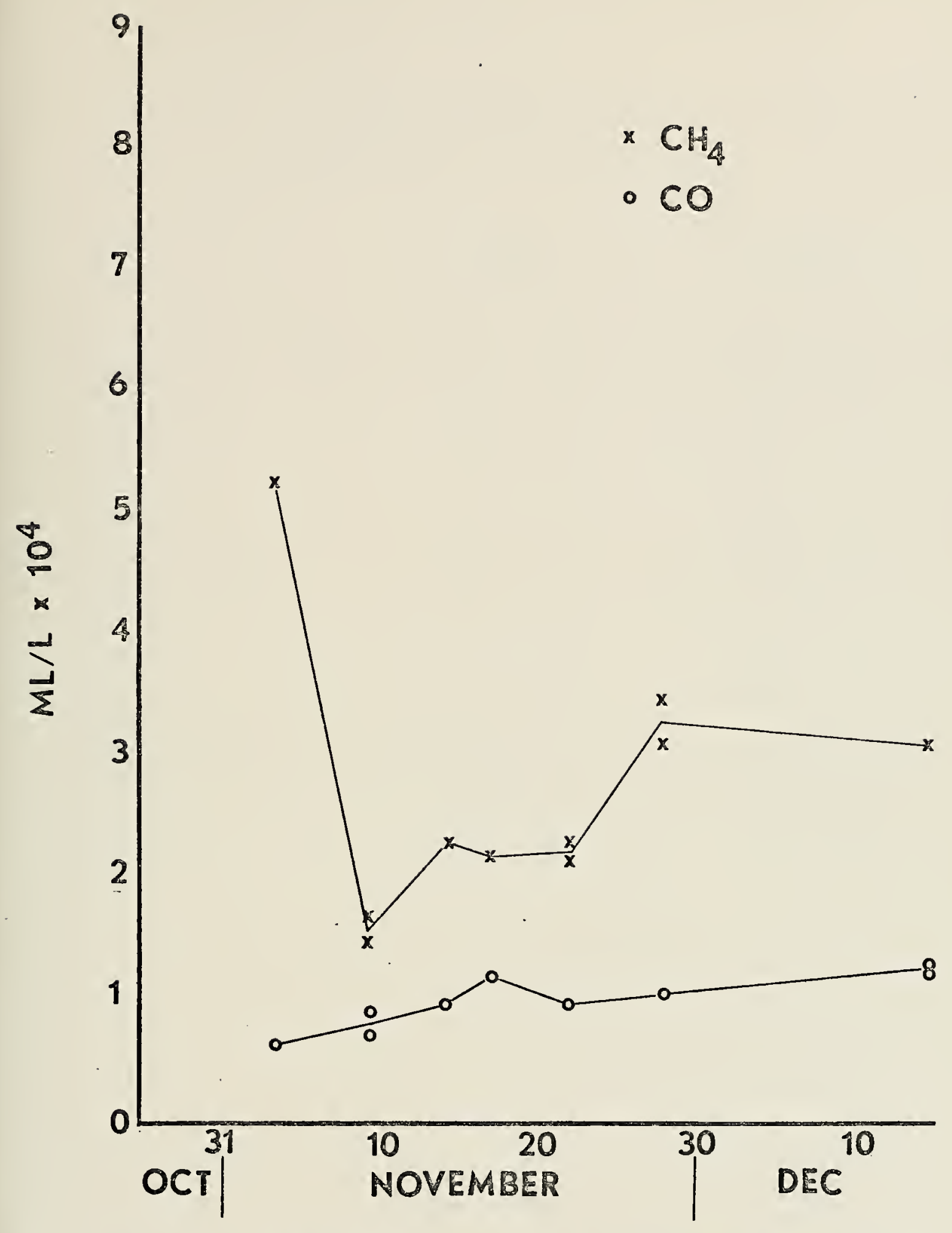

Figure 10. $\mathrm{CH}_{4}$ and $\mathrm{CO}$ concentrations in the surface waters at Point Cabrillo. 



\section{Table 5}

Methane and Carbon Monoxide

Concentrations at Point Cabrillo

$\begin{array}{lll}\text { Date } & \begin{array}{c}\text { Methane } \\ (\mathrm{m} 1 / 1)\end{array} & \begin{array}{c}\text { Carbon Monoxide } \\ (\mathrm{m} 1 / 1)\end{array} \\ 11-03-72 & 5.273 \times 10^{-4} & 0.677 \times 10^{-4} \\ 11-09-72 & 1.714 \times 10^{-4} & 0.942 \times 10^{-4} \\ 11-09-72 & 1.499 \times 10^{-4} & 0.733 \times 10^{-4} \\ 11-14-72 & 2.323 \times 10^{-4} & 0.983 \times 10^{-4} \\ 11-17-72 & 2.219 \times 10^{-4} & 1.209 \times 10^{-4} \\ 11-21-72 & 2.323 \times 10^{-4} & 0.955 \times 10^{-4} \\ 11-21-72 & 2.152 \times 10^{-4} & 1.006 \times 10^{-4} \\ 11-28-72 & 3.106 \times 10^{-4} & 1.066 \times 10^{-4} \\ 11-28-72 & 3.478 \times 10^{-4} & 1.097 \times 10^{-4} \\ 12-15-72 & 3.117 \times 10^{-4} & 1.242 \times 10^{-4} \\ 12-15-72 & 3.096 \times 10^{-4} & 1.305 \times 10^{-4}\end{array}$





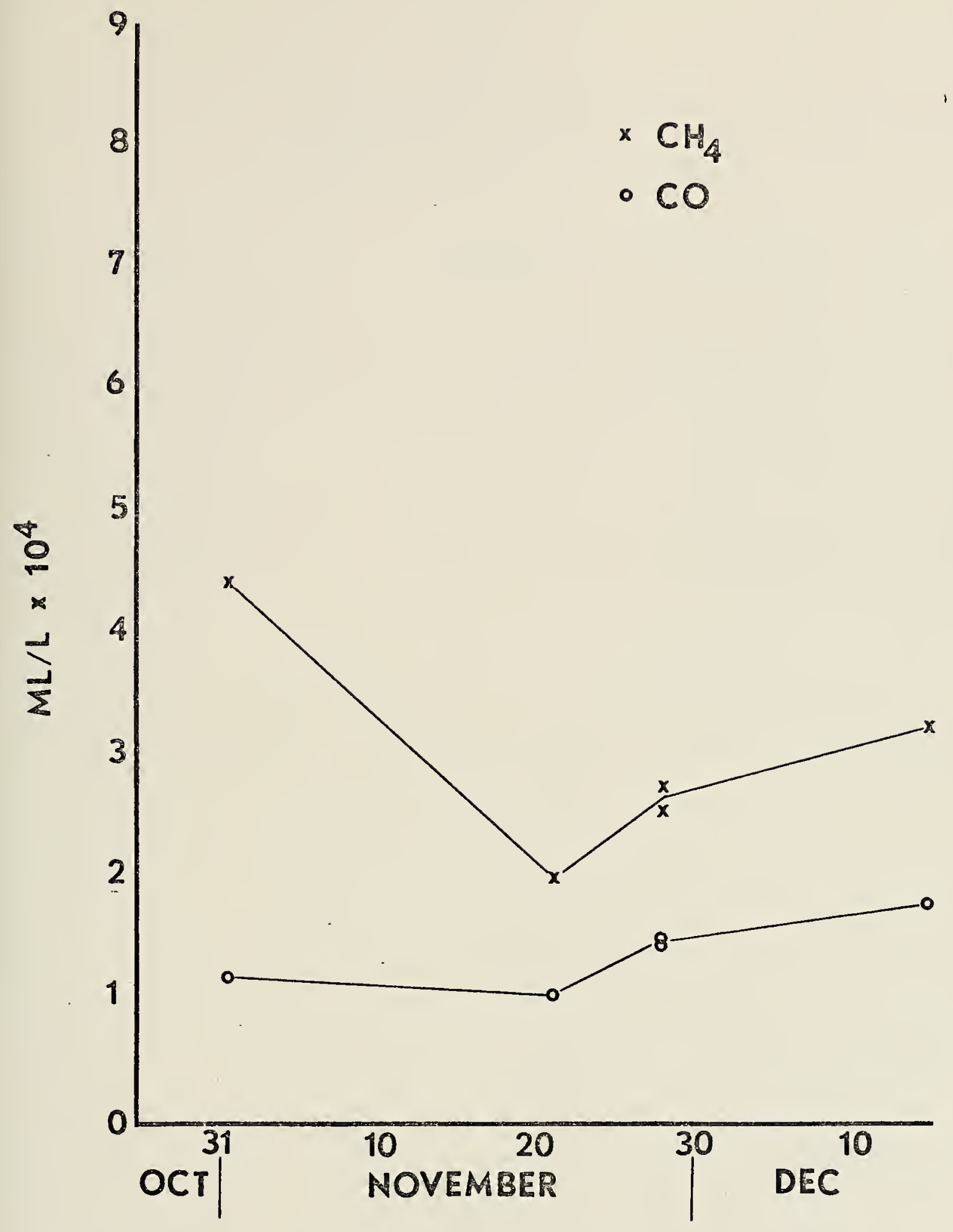

Figure 11. $\mathrm{CH}_{4}$ and $\mathrm{CO}$ concentrations in the surfaceswaters at Point Pinos North. 

Table 6

Methane and Carbon Monoxide

Concentrations at Point Pinos North

$\begin{array}{ccc}\text { Date } & \frac{\begin{array}{c}\text { Methane } \\ (\mathrm{m} 1 / 1)\end{array}}{1.437 \times 10^{-4}} & \begin{array}{c}\text { Carbon Monoxide } \\ (\mathrm{m} 1 / 1)\end{array} \\ 10-31-72 & 2.014 \times 10^{-4} & 1.085 \times 10^{-4} \\ 11-21-72 & 2.791 \times 10^{-4} & 1.531 \times 10^{-4} \\ 11-28-72 & 2.587 \times 10^{-4} & 1.467 \times 10^{-4} \\ 11-28-72 & 3.267 \times 10^{-4} & 1.833 \times 10^{-4} \\ 12-15-72 & 4.203 \times 10^{-4}\end{array}$





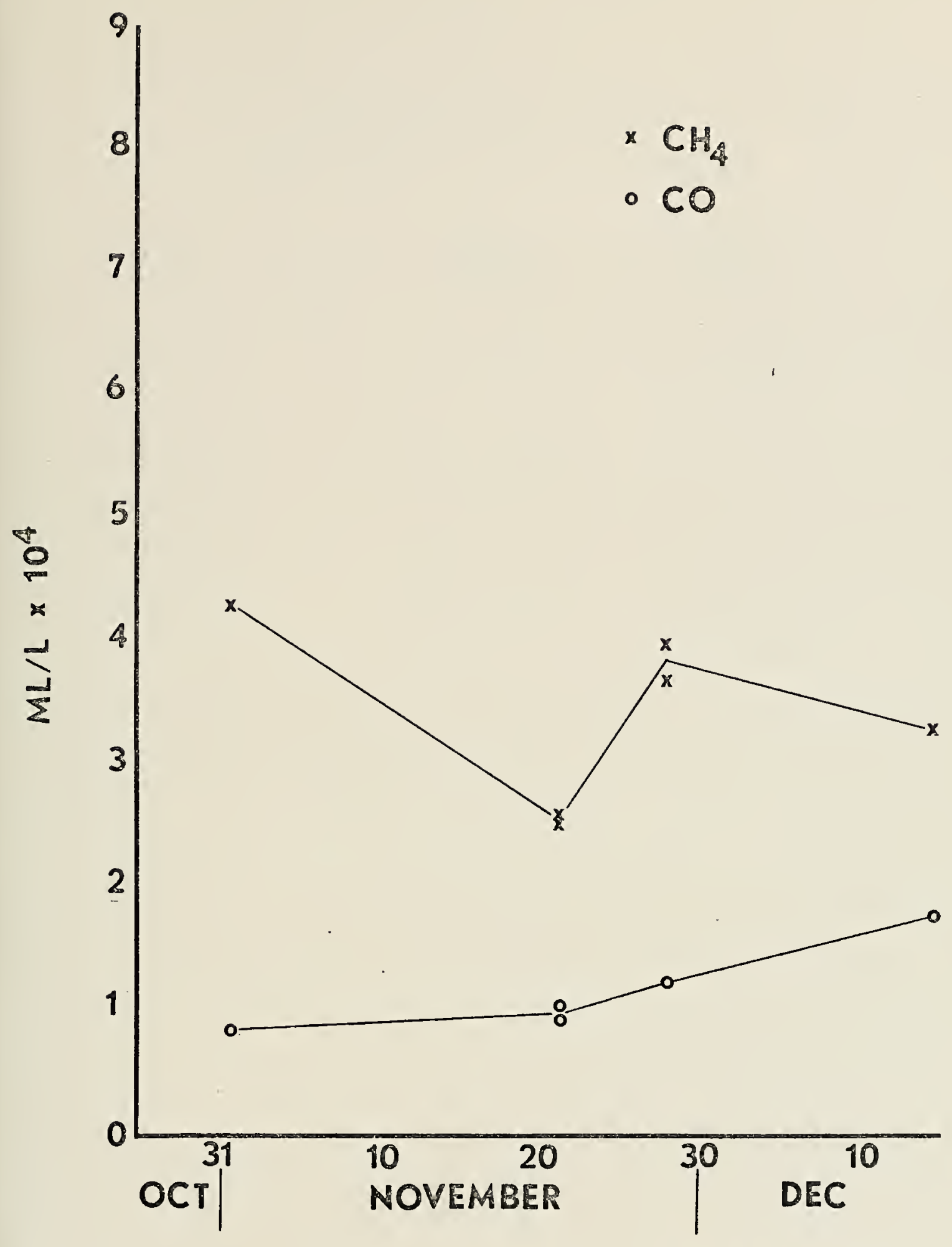

Figure 12. $\mathrm{CH}_{4}$ and $\mathrm{CO}$ concentrations in the surface waters at Point Pinos South. 



\section{Table 7}

\section{Methane and Carbon Monoxide}

Concentrations at Point Pinos South

$\begin{array}{ccr}\text { Date } & \begin{array}{c}\text { Methane } \\ (\mathrm{m} 1 / 1)\end{array} & \begin{array}{c}\text { Carbon Monoxide } \\ (\mathrm{m} 1 / 1)\end{array} \\ 10-31-72 & 4.317 \times 10^{-4} & 0.875 \times 10^{-4} \\ 11-21-72 & 2.527 \times 10^{-4} & 0.952 \times 10^{-4} \\ 11-21-72 & 2.635 \times 10^{-4} & 1.061 \times 10^{-4} \\ 11-28-72 & 3.998 \times 10^{-4} & 1.288 \times 10^{-4} \\ 11-28-72 & 3.694 \times 10^{-4} & 1.251 \times 10^{-4} \\ 12-15-72 & 3.481 \times 10^{-4} & 1.798 \times 10^{-4}\end{array}$





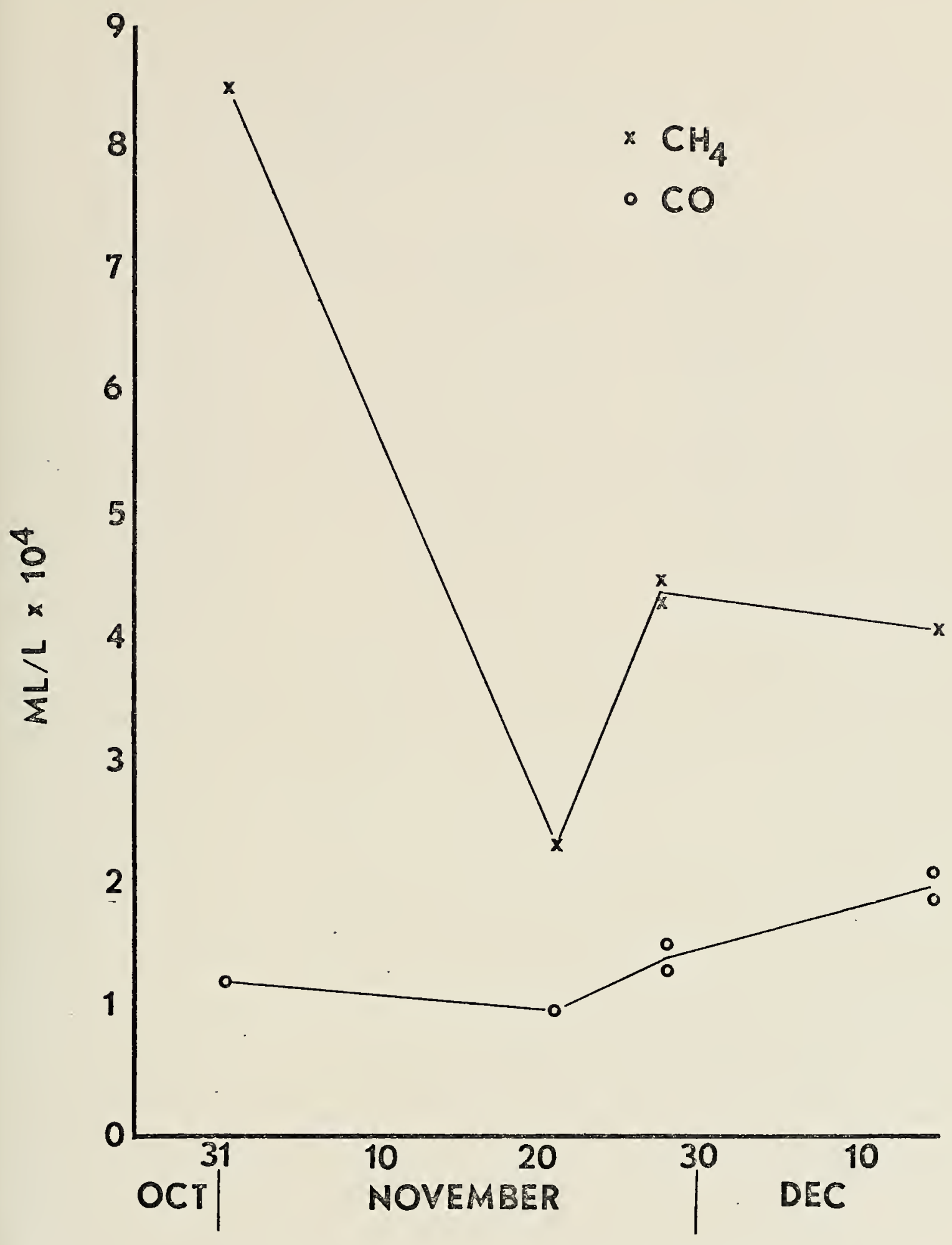

Figure 13. $\mathrm{CH}_{4}$ and $\mathrm{CO}$ concentrations in the surface waters at Point Joe. 



\section{Table 8}

Methane and Carbon Monoxide

Concentrations at Point Joe

Date

Methane

$(\mathrm{ml} / 1)$

$8.524 \times 10^{-4}$

$2.300 \times 10^{-4}$

$4.267 \times 10^{-4}$

$4.501 \times 10^{-4}$

$4.088 \times 10^{-4}$

$4.073 \times 10^{-4}$
Carbon Monoxide

$\frac{(\mathrm{ml} / 1)}{1.275 \times 10^{-4}}$
$1.034 \times 10^{-4}$
$1.548 \times 10^{-4}$
$1.344 \times 10^{-4}$
$2.109 \times 10^{-4}$
$1.903 \times 10^{-4}$





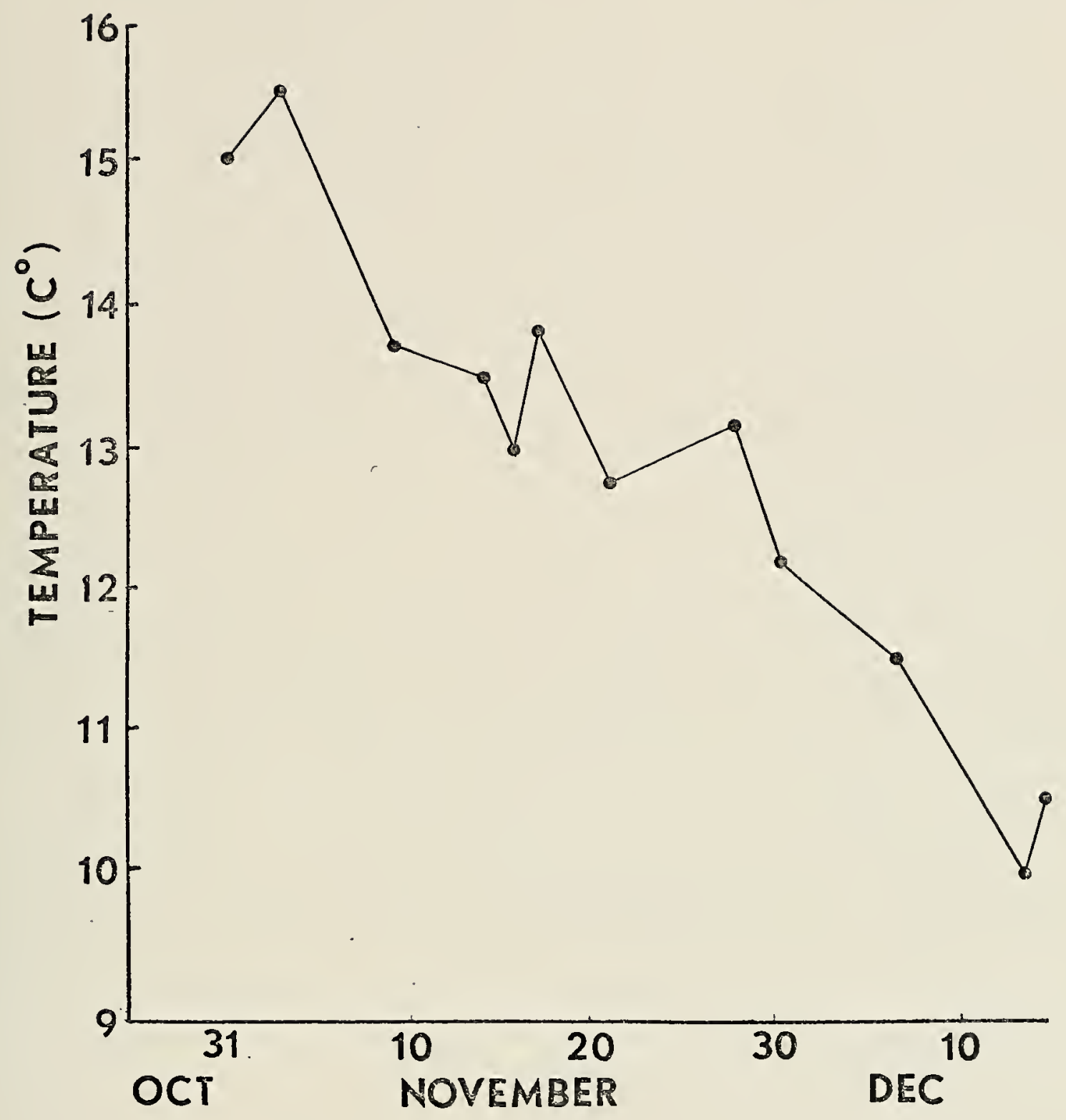

Figure 14. Surface temperature. 



\section{TRANSECTS}

The transect across Del Monte Beach proved most interesting. It started 400 yards east of the Monterey sewage disposal plant outfall and proceeded towards the harbor. Figure 16 and Table 9 show the results of this transect. The initial values of methane and carbon monoxide were low and then increased sharply at the "boil" above the outfall. Concentrations dropped back down west of the "boil" and then started to increase again as the stations got closer to Monterey harbor.

The transects from Del Monte Beach to the R-4 buoy (Figure 17 and Table 10) showed a wide variation in concentrations. On 1 December 1972, the methane decreased slightly to the first station beyond the kelp bed and then increased out to the buoy. Carbon monoxide increased slighty beyond the kelp and then remained fairly constant. On 14 December 1972, the methane followed the same pattern, but the drop in concentration from the kelp bed to the first open water station was much greater. Carbon monoxide seemed to decrease slightly beyond the kelp bed and then build up seaward.

The transect from Point Catrillo to the $\mathrm{R}-4$ buoy (Figure 18 and Table 11) showed very little change in either gas. Methane increased by $.1 \times 10^{-4}$ $\mathrm{m} 1 / 1$ from $3.1 \times 10^{-4} \mathrm{ml} / 1$ and carbon monoxide decreased $.4 \times 10^{-4} \mathrm{~m} 1 / 1$ from $1.3 \times 10^{-4} \mathrm{~m} 1 / 1$. 



\section{$\times \mathrm{CH}_{4}$ \\ - CO}

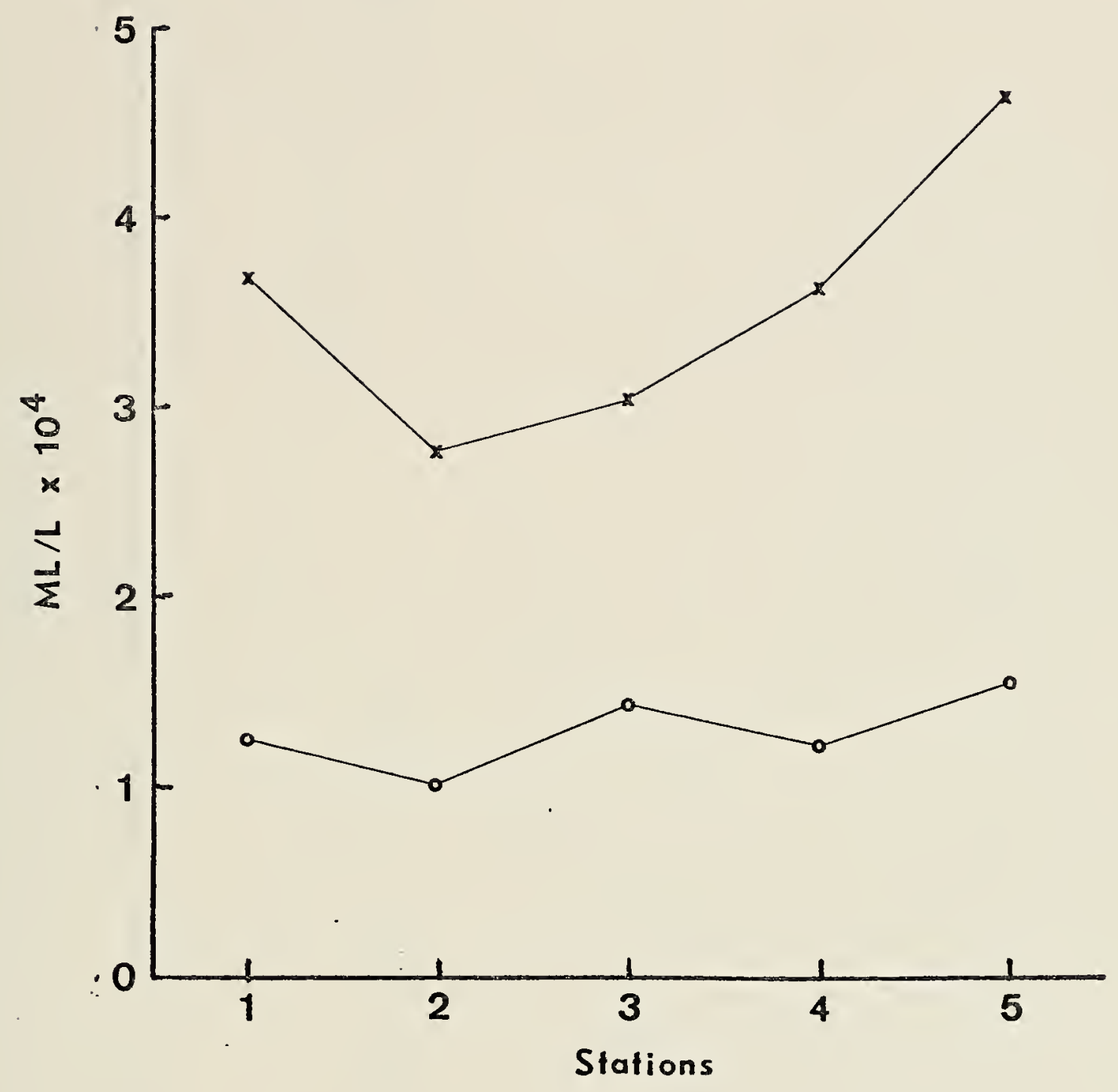

Figure 15. $\mathrm{CH}_{4}$ and $\mathrm{CO}$ gradients between the five nearshore stations. 



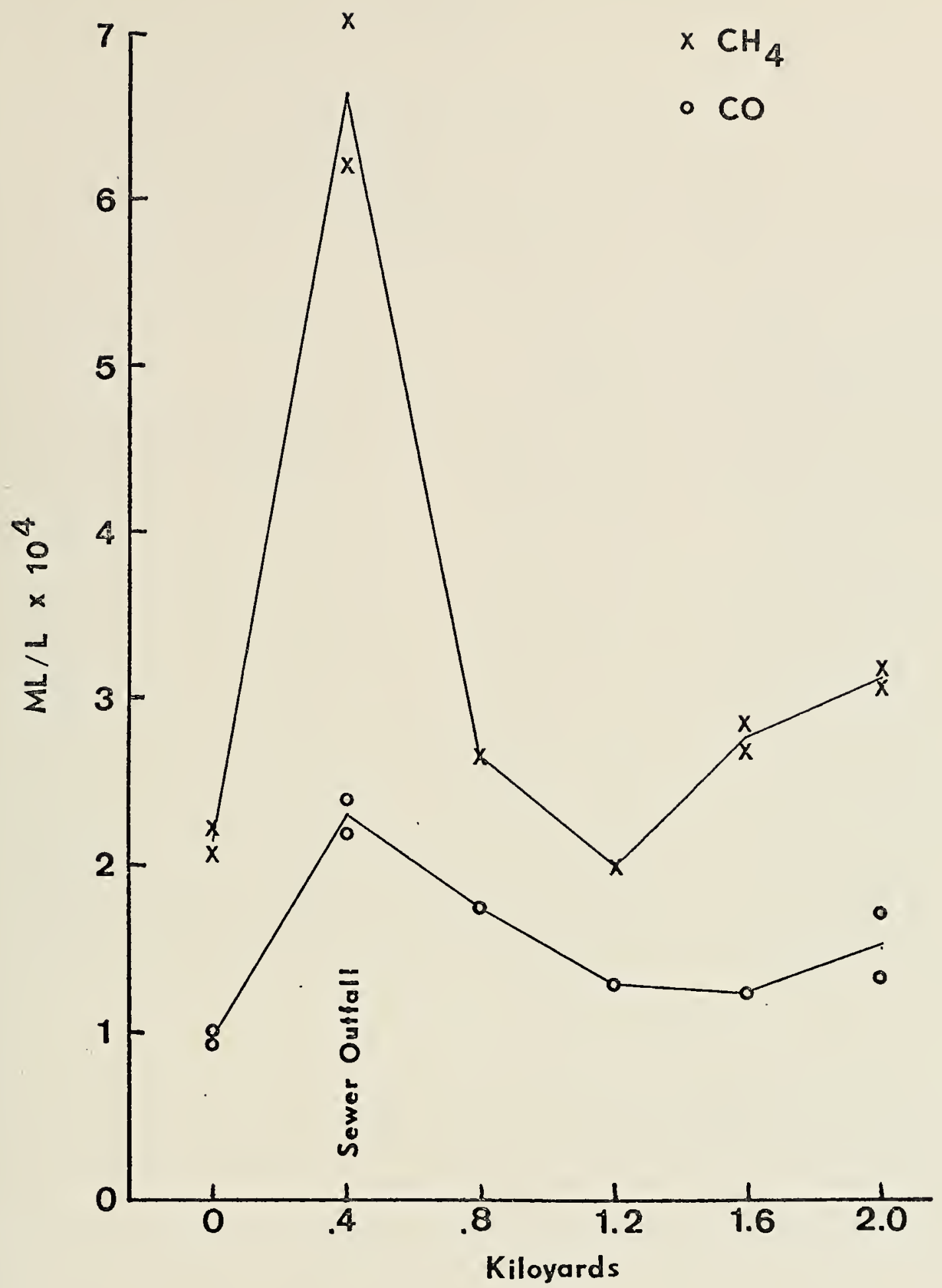

Figure 16. $\mathrm{CH}_{4}$ and $\mathrm{CO}$ concentrations for a transect along Del Monte Beach". 

:Table 9

Methane and Carbon Monoxide

Concentrations for the Transect Along

1 Del Monte Beach

Date ¡Location

Methane

Carbon Monoxide

$(\mathrm{ml} / 1)$

$(\mathrm{m} 1 / 1)$

$\begin{array}{lcll}11-16-72 & \text { Kelp Edge } & 2.214 \times 10^{-4} & 0.935 \times 10^{-4} \\ 11-16-72 & \text { Kelp Edge } & 2.089 \times 10^{-4} & 1.040 \times 10^{-4} \\ 11-16-72 & \text { Sewer Outfal1 } & 7.053 \times 10^{-4} & 2.380 \times 10^{-4} \\ 11-16-72 & \text { Sewer Outfa11 } & 6.198 \times 10^{-4} & 2.191 \times 10^{-4} \\ 11-16-72 & \text { Pump House } & 2.631 \times 10^{-4} & 1.763 \times 10^{-4} \\ 11-16-72 & \text { Beach lab } & 1.995 \times 10^{-4} & 1.276 \times 10^{-4} \\ 11-16-72 & \text { Apartments } & 2.823 \times 10^{-4} & 1.222 \times 10^{-4} \\ 11-16-72 & \text { Apartments } & 2.673 \times 10^{-4} & 1.241 \times 10^{-4} \\ 11-16-72 & \text { Public Beach } & 3.161 \times 10^{-4} & 1.172 \times 10^{-4} \\ 11-16-72 & \text { Public Beach } & 3.054 \times 10^{-4} & 3.054 \times 10^{-4}\end{array}$





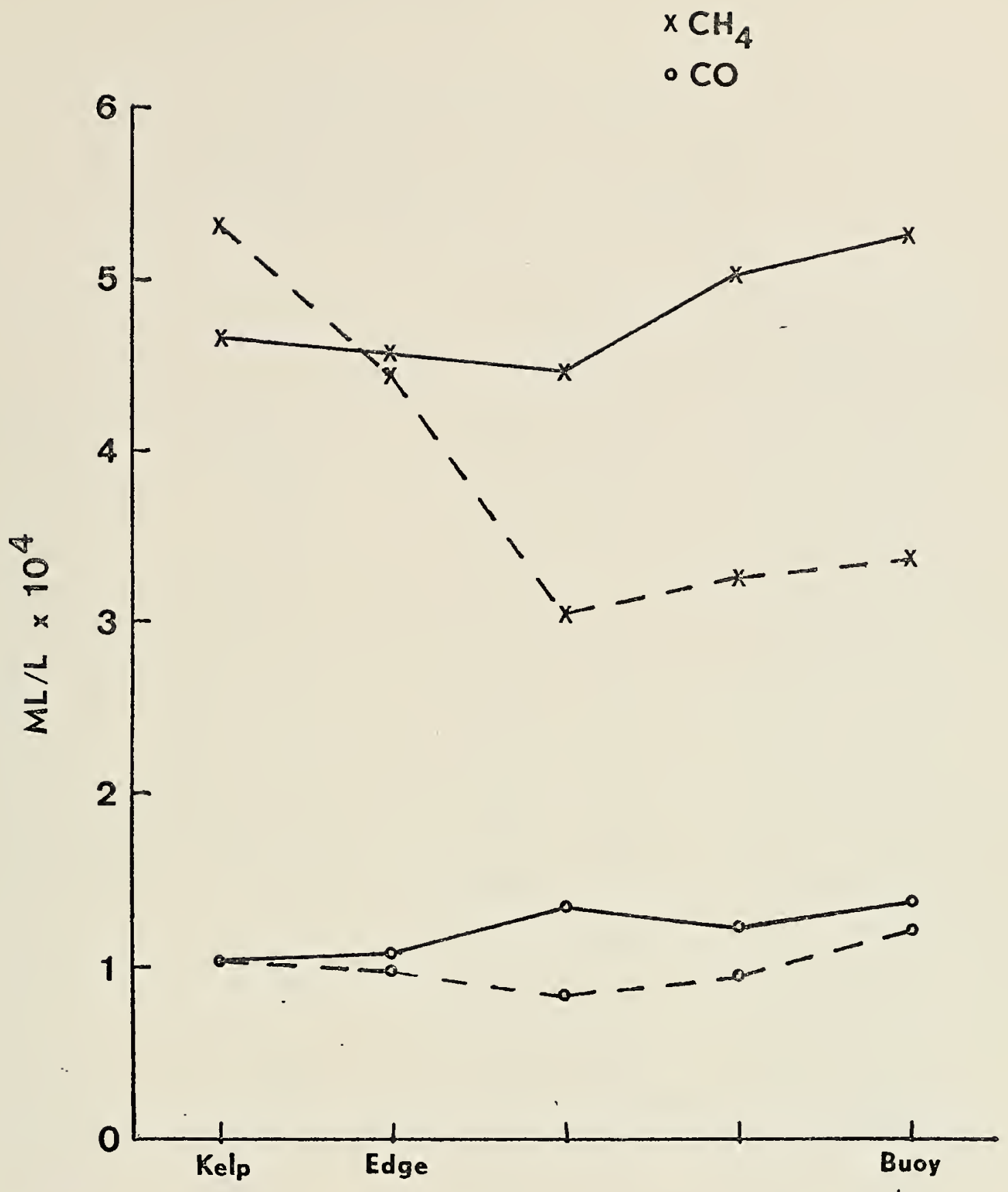

Figure 17. $\mathrm{CH}_{4}$ and $\mathrm{CO}$ concentrations from transects from Del Monte Beach to the R-4 Buoy. Solid 1 ine is data for 1 December 1972 and dashed line is data for 14 December 1972. 

Methane and Carbon Monoxide

Concentrations for the Transect from

Del Monte Beach to the R-4 Buoy

Date Location

\begin{tabular}{|c|c|c|c|}
\hline $12-01-72$ & Station & $4.682 \times 10^{-4}$ & $1.039 \times 10^{-4}$ \\
\hline $12-01-72$ & Kelp Edge & $4.517 \times 10^{-4}$ & $1.041 \times 10^{-4}$ \\
\hline $12-01-72$ & Kelp Edge & $4.609 \times 10^{-4}$ & $1.080 \times 10^{-4}$ \\
\hline $12-01-72$ & Open Water 1 & $4.490 \times 10^{-4}$ & $1.330 \times 10^{-4}$ \\
\hline $12-01-72$ & Open Water 1 & $4.433 \times 10^{-4}$ & $1.389 \times 10^{-4}$ \\
\hline $12-01-72$ & Open Water 2 & $4.965 \times 10^{-4}$ & $1.272 \times 10^{-4}$ \\
\hline $12-01-72$ & Open Water 2 & $5.105 \times 10^{-4}$ & $1.271 \times 10^{-4}$ \\
\hline $12-\theta 1-72$ & Station & $5.287 \times 10^{-4}$ & $1.416 \times 10^{-4}$ \\
\hline $12-01-72$ & Station 6 & $5.233 \times 10^{-4}$ & $1.397 \times 10^{-4}$ \\
\hline $12-14-72$ & Station & $5.358 \times 10^{-4}$ & $1.046 \times 10^{-4}$ \\
\hline $12-14-72$ & Station 1 & $5.277 \times 10^{-4}$ & $1.082 \times 10^{-4}$ \\
\hline $12-14-72$ & Kelp Edge & $4.374 \times 10^{-4}$ & $0.990 \times 10^{-4}$ \\
\hline $12-14-72$ & Kelp Edge & $4.594 \times 10^{-4}$ & $1.143 \times 10^{-4}$ \\
\hline $12-14-72$ & Open Water 1 & $2.924 \times 10^{-4}$ & $0.856 \times 10^{-4}$ \\
\hline $12-14-72$ & Open Water 1 & $3.120 \times 10^{-4}$ & $0.854 \times 10^{-4}$ \\
\hline $12-14-72$ & Open Water 2 & $3.277 \times 10^{-4}$ & $0.997 \times 10^{-4}$ \\
\hline $12-14-72$ & Station & $3.382 \times 10^{-4}$ & $1.223 \times 10^{-4}$ \\
\hline
\end{tabular}

Methane

(m1/1)

Carbon Monoxide

(ml/1) 



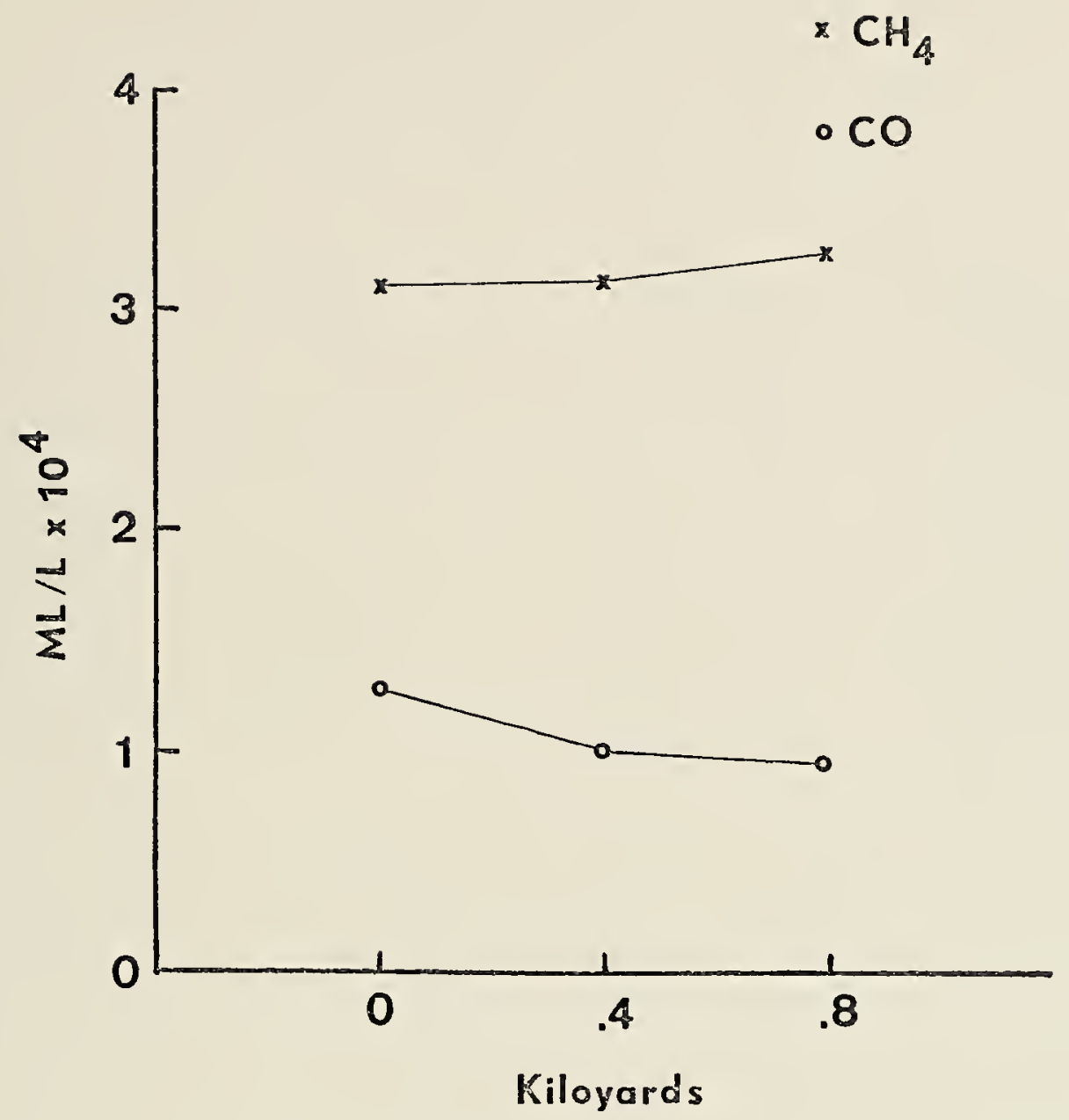

Figure 18. $\mathrm{CH}_{4}$ and $\mathrm{CO}$ concentrations for a transect from Point Cabrillo to the R-4 Bell Buoy. 

Table 11

Methane and Carbon Monoxide

Concentrations for the Transect from

Point Cabrillo to the R-4 Buoy

Date Location

-

12-15-72 Station 2

12-15-72 Station 2

12-15-72 Intermediate

12-15-72 Intermediate

12-15-72 Station 6
Methane

$\underline{(\mathrm{ml} / 1)}$

$3.117 \times 10^{-4}$

$3.096 \times 10^{-4}$

$3.091 \times 10^{-4}$

$3.136 \times 10^{-4}$

$3.231 \times 10^{-4}$
Carbon Monoxide (m1/1)

$1.242 \times 10^{-4}$

$1.305 \times 10^{-4}$

$0.970 \times 10^{-4}$

$1.024 \times 10^{-4}$

$0.932 \times 10^{-4}$ 



\section{DISCUSSION OF RESULTS}

\section{A. PRECISION AND ACCURACY}

The precision and accuracy of the gas chromatograph system was checked by running ten consecutive calibration checks. The average of these ten runs was computed as well as the RMS deviation. It was found that to be within plus or minus two RMS deviations, errors as large as $10 \%$ could be expected for carbon monoxide and $7.8 \%$ for methane.

These errors came mainly from the peak area measurements. First, the determination of a base line proved a problem if there was any drift in the system. To minimize this, the same method of baseline determination was used in each run. This may not eliminate the error, but it should keep it constant.

Area calculation by peak height and width at half height measurement only approximates actual peak area. To solve this problem, either the very careful use of a planimeter, cutting out the peaks and weighing them, or an automatic integrator could be used. These first two unfortunately have the problem of increased analysis time, and the last one, high cost.

\section{B. OPEN OCEAN DEEP STATION}

The comparison of Figures 7 and 8 shows a striking correspondence between carbon monoxide concentrations and primary productivity. These results seem to give support to the hypothesis that phytoplankton may be producing carbon monoxide, but this is unexpected and requires experimental verification.

Some anaerobic, methanogenic bacteria are known to convert carbon monoxide to methane (Pine 1971, Jaffe 1970). Figure 19 shows an increase 

in both methane and carbon monoxide from the surface to 15 meters. If the carbon monoxide production is related to phytoplankton, and if methane is produced anaerobically in situ (or carried there from an anaerobic source) this could explain the concurrent increase of these gases in the surface layer. From 15-100 meters, the carbon monoxide decreases, but the methane continues to increase. This may show continued bacterial conversion of carbon monoxide to methane below the layer of high productivity, or the advection of a methane rich water mass in the upper 100 meters.

Below 100 meters both gases decrease with depth.

\section{c. TEMPORAL STUDY}

The temporal study showed a marked difference between the stations in Monterey Bay (Stations 1 and 2) and those on the exposed coast. Station 1 at Del Monte Beach showed great variability in both methane and carbon monoxide (Figure 9). This was expected since there are many more factors affecting these gases in this environment; sewage disposal plant effluent, pollution from Monterey harbor, and city storm sewer outlets all contribute to the water budget of this station. It is interesting to compare the values of primary productivity with the methane concentrations. They both show marked decrease following the onset of the first storm and then both increase throughout the rest of the study. Carbon monoxide does not show any correlation with primary productivity at this station. The cause for the large jump in carbon monoxide concentration during the period 16-28 November 1972 is unknown. It is possible that this variability in concentrations was present at the other stations and that the more frequent sampling of De1 Monte Beach merely showed the transient nature of these gases.

Point Cabrillo (Station 2), still being within the confines of the 



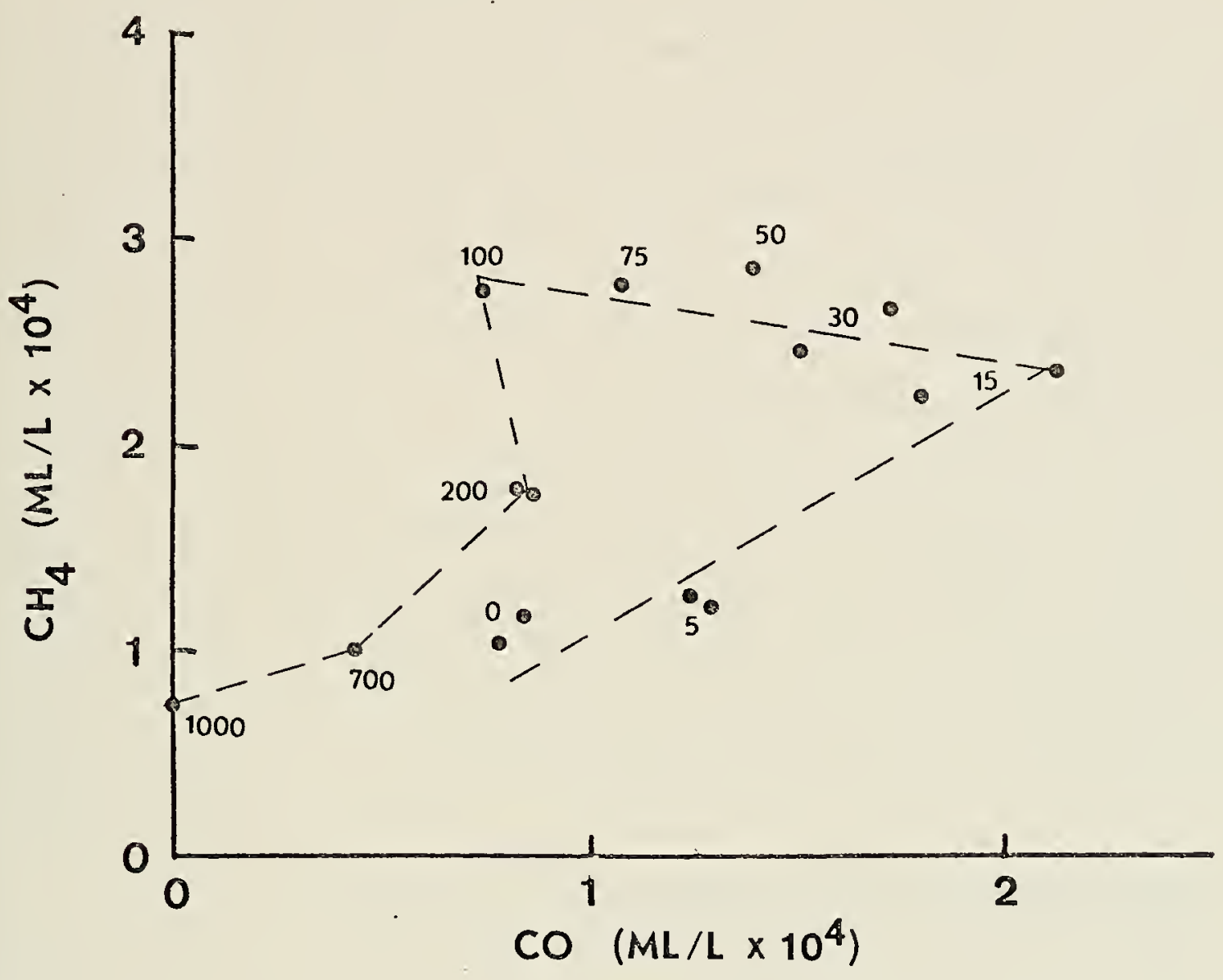

Figure 19. Plot of $\mathrm{CH}_{4}$ vs. $\mathrm{CO}$ in the Deep Ocean Station in the Monterey Canyon. Numbers indicate depth in meters. 

bay, had characteristics similar to those found at Del Monte Beach. Since it was further removed from the sources of the pollutants at Del Monte Beach, the variability was not as great. There was still a parallel trend between methane and primary productivity, and none noted for carbon monoxide.

Station 3 at Point Pinos North is subject to the heavy surf action from oceanic waves. Like stations 1 and 2 , it, too, showed close correlation between methane and primary productivity, but it also showed a trend between carbon monoxide and primary productivity after the heavy rains.

Station 4 was located just off the Pacific Grove sewage disposal plant outfall at Point Pinos. Here, the methane-primary productivity and the post storm carbon monoxide-primary productivity correlations were both good. It was interesting to note that little or no idfluence from the sewage effluent was noted in the kelp bed off shore, wile the rocks near the outfall appeared to be devoid of life. This probably shows the diluting effect on the heavily chlorinated sewage of the turbulent mixing from the surf in this area.

Station 5 at Point Joe initially showed exceptionally high methane concentrations. Following the first storm, this was reduced to values comparable to the other four stations. Following the rains, it increased more rapidly than any other station. These high methane concentrations seem to indicate a methane source near Point Joe. It is very possible that this source is the Pebble Beach sewage outfal1, located just south of Point Joe, where apparently untreated sewage is dumped directly into the ocean.

When the methane concentration was exceptionally high, primary productivity was low. This does not follow the pattern set by the other four 

stations. It is possible that phytoplankton growth is inhibited when methane concentrations reach a certain toxic level, or both may be affected by a third factor. After the rains, and subsequent decrease in methane concentrations, the correlation between methane and primary productivity was again apparent.

Carbon monoxide and primary productivity showed very good correlations throughout the sampling period at this station.

\section{GRADIENT ANALYSIS}

The gradient analysis (Figure 15) indicates the possibility of methane sources at Del Monte Beach and Point Joe. Since the high methane gradients exist at or near sewage disposal plant outfalls, this supports the hypothesis that methane can be used as a tracer for sewage effluent.

The carbon monoxide gradient was not as dramatic as that for methane. It also showed the highest value at Point Joe. An examination of the plant population of point Joe may help explain this. Stations 1 through 4 are predominantly Macrocystis pyrifera while station 5 is mainly Nereocystis 1eutkeana. Loewus and Delwiche (1963) have shown that Nereocystis leutkeana produces three times as much carbon monoxide as Macrocystis pyrifera. Therefore, one would expect higher carbon monoxide concentrations at Point Joe than at other stations. A closer examination of the macroalgae at each station might help to explain the variation in the carbon monoxide gradients.

The open ocean value of $1.1 \times 10^{-4} \mathrm{~m} 1 / 1$ measured in the Monterey Canyon is 2.4 times the equilibrium concentration of methane in seawater (assuming methane content of air is $1.24 \mathrm{ppm}$ ). Similarly, the carbon monoxide concentration of $0.81 \times 10^{-4} \mathrm{ml} / 1$ is 22.5 times the equilibrium concentration (assuming the highest reported oceanic partial pressure for 

carbon monoxide of $0.17 \mathrm{ppm}$ ). The average concentration for both carbon monoxide and methane at each station was considerably higher than the oceanic value. Therefore, it is likely that these kelp beds are sources of these gases to the atmosphere.

\section{E. TRANSECTS}

The transects from Del Monte Beach to the $R-4$ buoy showed the effect of the rains on these gases. Before the rains, the concentrations of both gases in the kelp bed and in the open water were high. After the rains, the values in the kelp were high, but the open water values were decreased substantially. This may show the effect of the kelp as an inhibitor to the mixing process.

The transect from Point Cabrillo to the R-4 buoy showed essentially constant, low methane concentrations. This transect was taken after the rains, and since no methane source near Point Cabrillo was indicated in the gradient analysis, this type of profile could be expected.

The carbon monoxide, on the other hand, showed a decrease seaward. If, indeed, the macroalgae are producing carbon monoxide, this decrease away from the kelp bed could be expected.

Since the gradient analysis indicated a source of methane at Del Monte Beach, a transect was taken there to determine the source of the pollutant (Figure 16). As was expected, extremely high methane values were found in the "boil" above the sewage outfall. Since Monterey does not use an anaerobic treatment process, the source of this methane raised an interesting question.

One possibility was that organic matter was settling out around the outfal1. This could create anaerobic conditions and thus generate high concentrations of methane. This idea was abandoned after talking with divers who had frequented the area. 

The second premise was that the methane was already present before the sewage reached the treatment plant. This was substantiated by some early attempts to analyze tap water. The city water had so much methane in it that the electrometer in the gas chromatograph was immediately saturated and no value could be obtained.

There was also an indication that the harbor was also a source of both carbon monoxide and methane. With the leakage of petroleum products and the exhaust from power boats, it is no wonder that this was observed. 



\section{SUMMARY}

Results from the open ocean station and several nearshore stations show a possible correlation between carbon monoxide and primary productivity in this relatively pollution-free environment. Methane was also shown to be present in the upper 100 meters, showing a maximum at about 50 meters. This may indicate biological production of this gas in an oxygen rich environment.

At the nearshore stations, concentrations of methane and carbon monoxide were both far above equilibrium and open ocean values. It was shown that methane concentrations were highest in the vicinity of sewage outfalls and that the source of this gas may be the city water supply. Carbon monoxide concentrations may very well be dependent on the type of plant life in the surrounding waters.

Rain was shown to act as a depressant for methane concentrations and primary productivity, but had little effect on carbon monoxide. Methane in very high concentrations appeared to act as a poison to phytoplankton since primary productivity dropped dramatically in methane rich waters.

The transects showed that methane was an effective tracer for sewage disposal plant effluent and that the kelp seemed to slow the diffusion and mixing of pollutants.

From equilibrium considerations, the waters of Monterey Bay were found to be supersaturated with carbon monoxide and methane. The highest concentrations were, for the most part, located in the kelp beds. These results indicate that, at least locally, the ocean is a source of carbon monoxide and methane in the atmosphere. 



\section{RECOMMENDATIONS}

Further work with this system could prove valuable in the field of air-sea interaction. By incorporating an air sampling loop, direct measurements of interfacial gradients for a variety of components could be made. It would have been especially helpful in the present study to have known the atmospheric concentrations of these gases.

Due to the limitations of the gas chromatograph used, the hydrocarbons higher than methane that were trapped were not analyzed. In the future, a useful addition to the system would be a dual channel, dual detector gas chromatograph. This would allow simultaneous analysis of a wide variety of organics. The addition of a self-integrating recorder would provide the capability of making on-station, real-time measurements of these dissolved gases.

It is recommended that further work on carbon monoxide and methane be pursued in the Monterey Submarine Canyon. Paucity of ship time aboard $\mathrm{R} / \mathrm{V}$ Acania precluded further investigation of this area during this study. 

APPENDIX A

Analysis Procedures

Sample Transfer

1. Bottle on.

2. Open drain valve to sample bottle to remove old sample from line.

3. Turn drain valve to fill stripping chamber.

4. Turn transfer valve.

5. At $100 \mathrm{ml}$. turn off transfer valve.

6. Turn drain valve off at zero.

7. Open pressure release and close again.

\section{Stripping}

1. Place cold traps.

2. Valve Tl to Trap.

3. Valve $\mathrm{T} 2$ to Trap.

4. Trap/Anal valve to Trap.

5. Cal valve to $\mathrm{Cal}$ Fill.

6. Trap/Bypass to Trap.

7. Open trap isolation valves.

8. Ensure cap is on valve $\mathrm{Tl}$.

9. Open helium purge and start timer.

10. Turn on magnetic stirring bar.

11. Check exhaust flow (13).

12. Close trap isolation valves at $720 \mathrm{sec}$.

13. Drain 25 - $50 \mathrm{ml}$. from chamber. 

14. Switch Trap/Bypass valve to Bypass.

15. Leave helium flow on.

Ana1ysis

1. Remove cold traps.

2. Place hot water on Trap 2 .

3. Warm for one minute.

4. Place Trap/Ana1 valve to Ana1.

5. Set range and attenuation.

6. Zero recorder using Bucking Voltage (obtain baseline).

7. Turn recorder on Low (1"/min.)

8. Turn valve $\mathrm{T} 2$ to anal at reference line on recorder.

9. Analysis is complete in seven minutes.

\section{clean up}

1. Drain stripping chamber to about $475 \mathrm{ml}$.

2. Turn off purge helium.

3. Drain to $500 \mathrm{~m} 1$.

4. Place hot water on Trap 1.

5. Remove cap from T1.

6. Switch T1 to Ana1.

7. Warm for 1 minute.

8. Repalce cap on T1.

9. Remove hot water.

10. Remove sample bottle. 

Calibration (direct injection)

Valve T1 - Trap position.

Valve T2 - Trap position

Anal/Trap - Trap position

Cal valve - Gal Fill position

Trap/Bypass - Bypass position

Fill cal loop

Cal valve - $\mathrm{Cal}$ inj. position

Calibration (through traps)

Valve T1 - Trap position

Valve $\mathrm{T} 2$ - Trap position

Anal/Trap - Anal position

Cal valve - Cal Fill position

Trap/Bypass - Trap position

Fil1 Cal Loop

Cal valve - Gal inj. position

Run as if it were a sample, follow stripping and analysis procedure as in Appendix A.

Blank (Run before a series of samples)

Valve T1 - Trap position

Valve T2 - Trap position

Trap/Bypass - Trap position

Cal valve - not important

Run degassed sample, follow stripping and analysis procedures in Appendix A to clear system or check for purge gas contamination. 



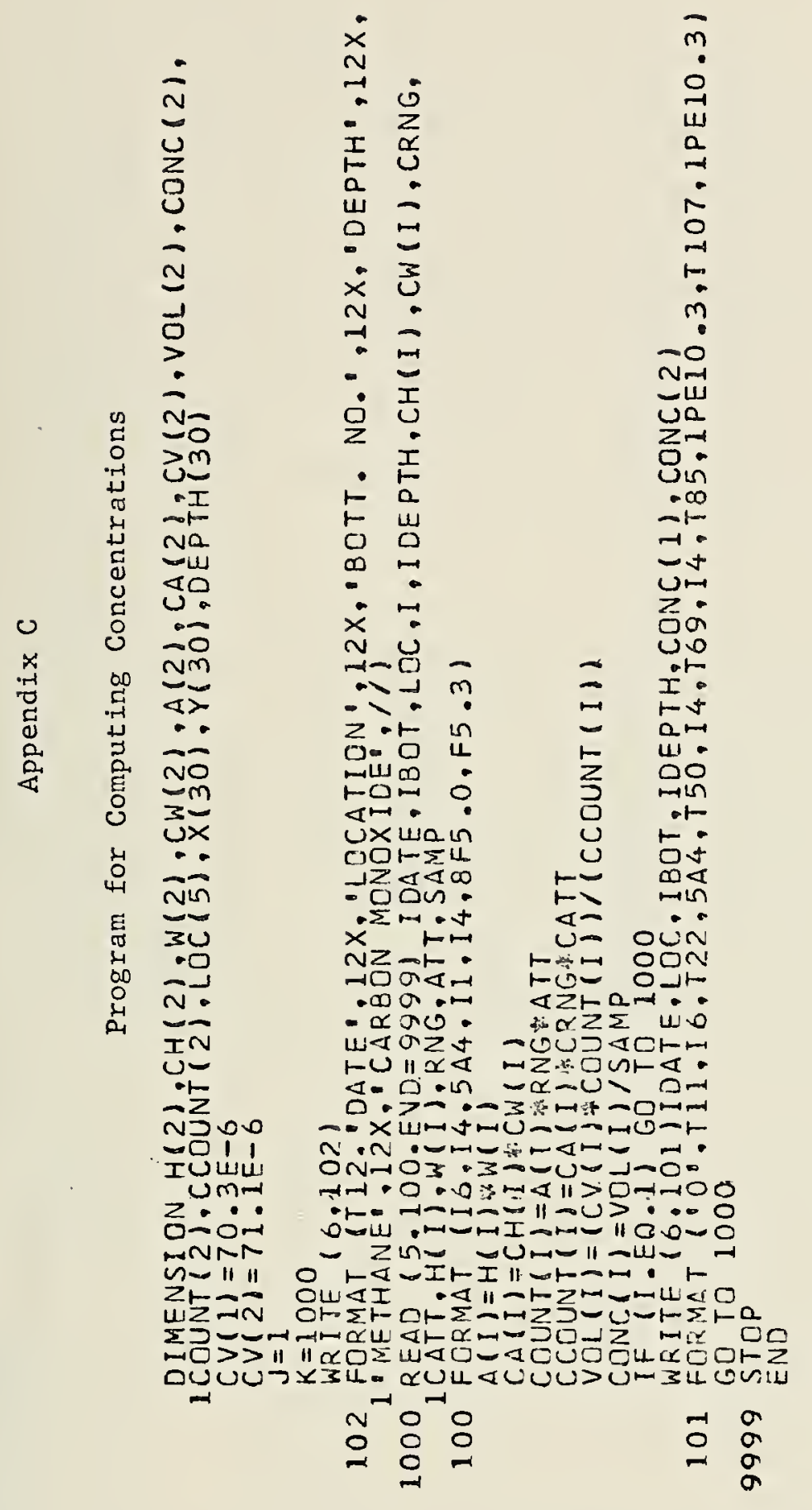





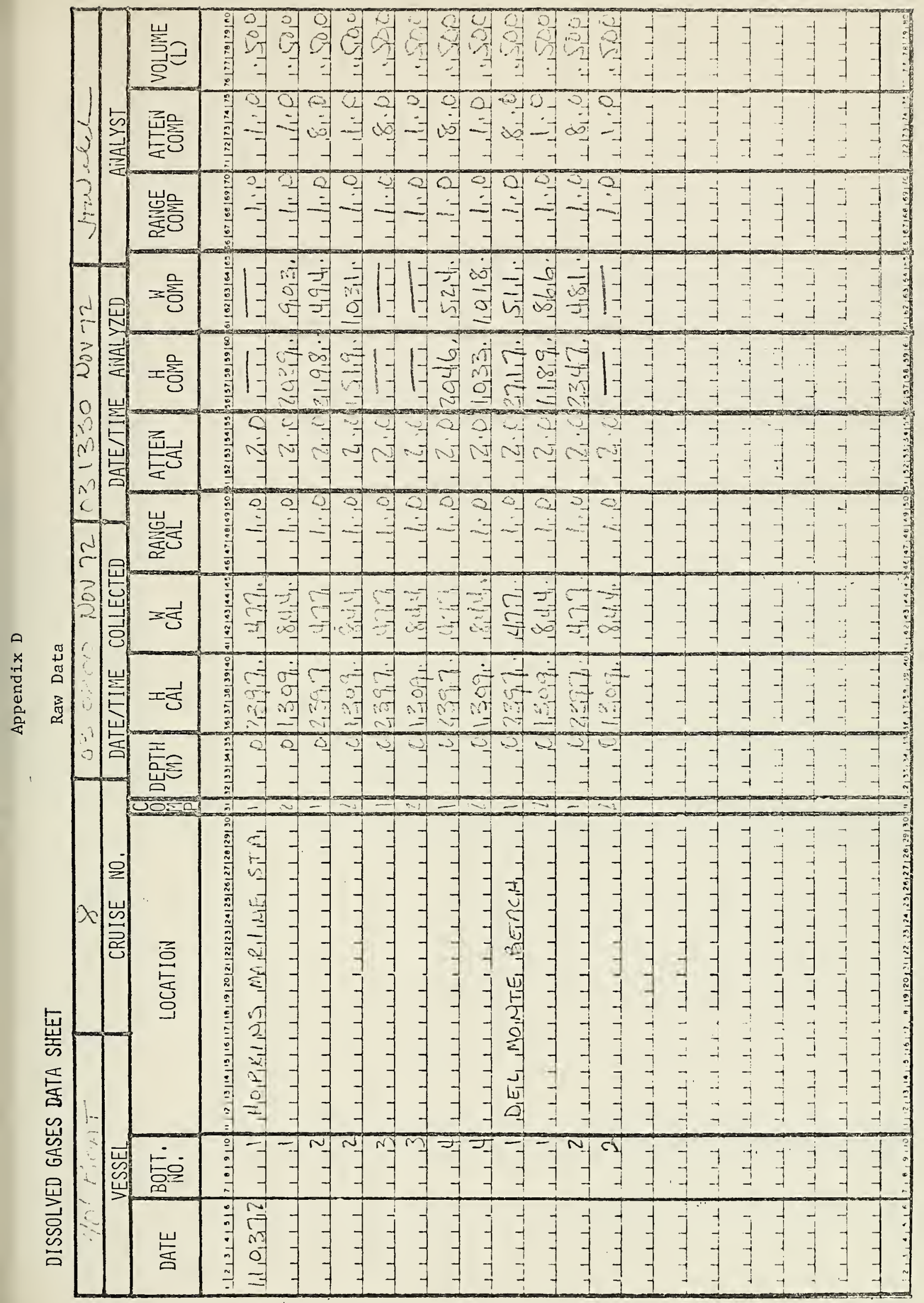





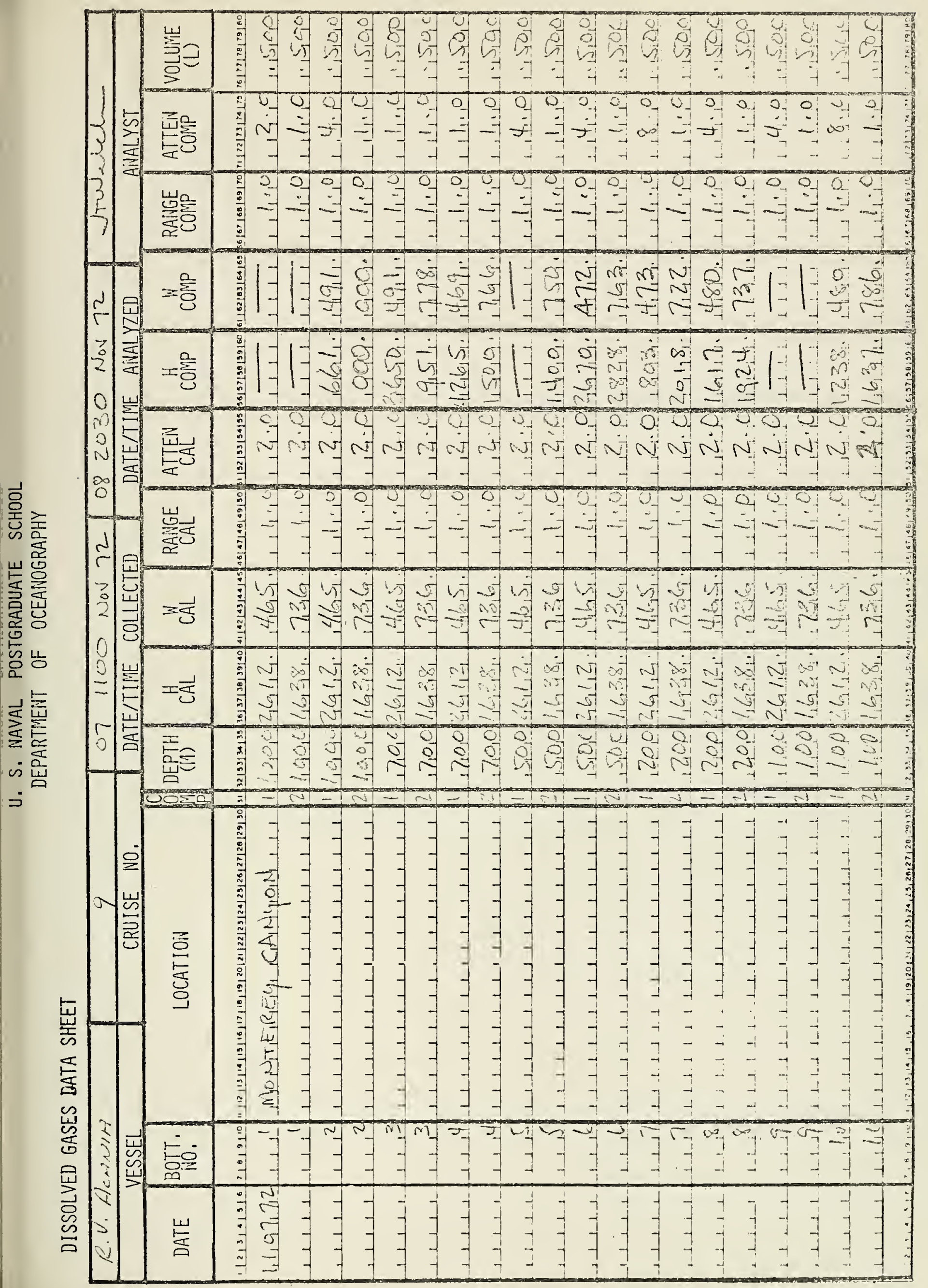








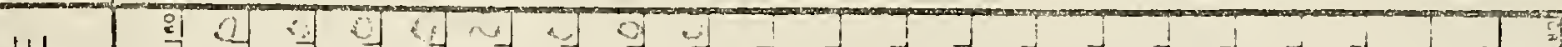





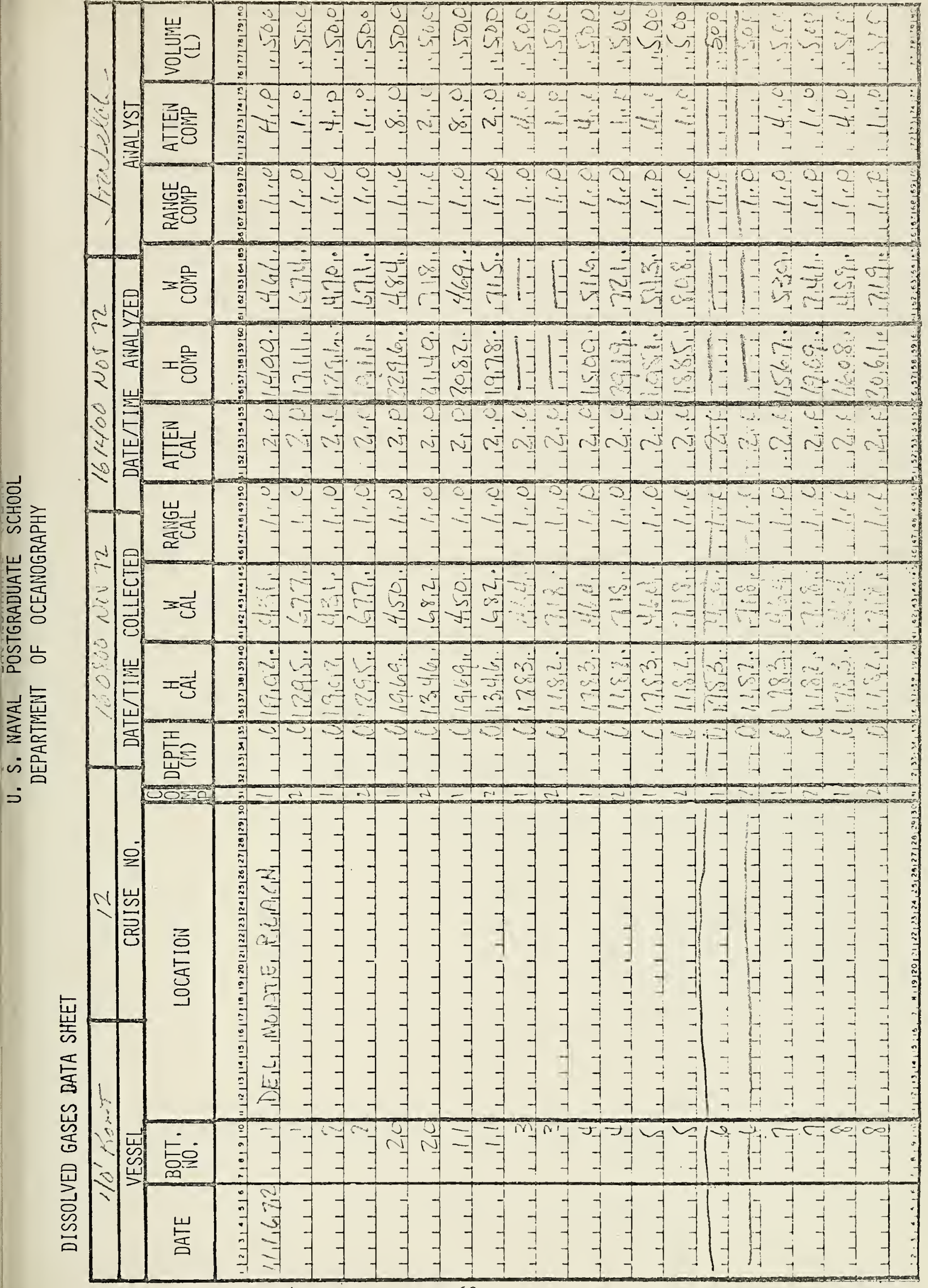





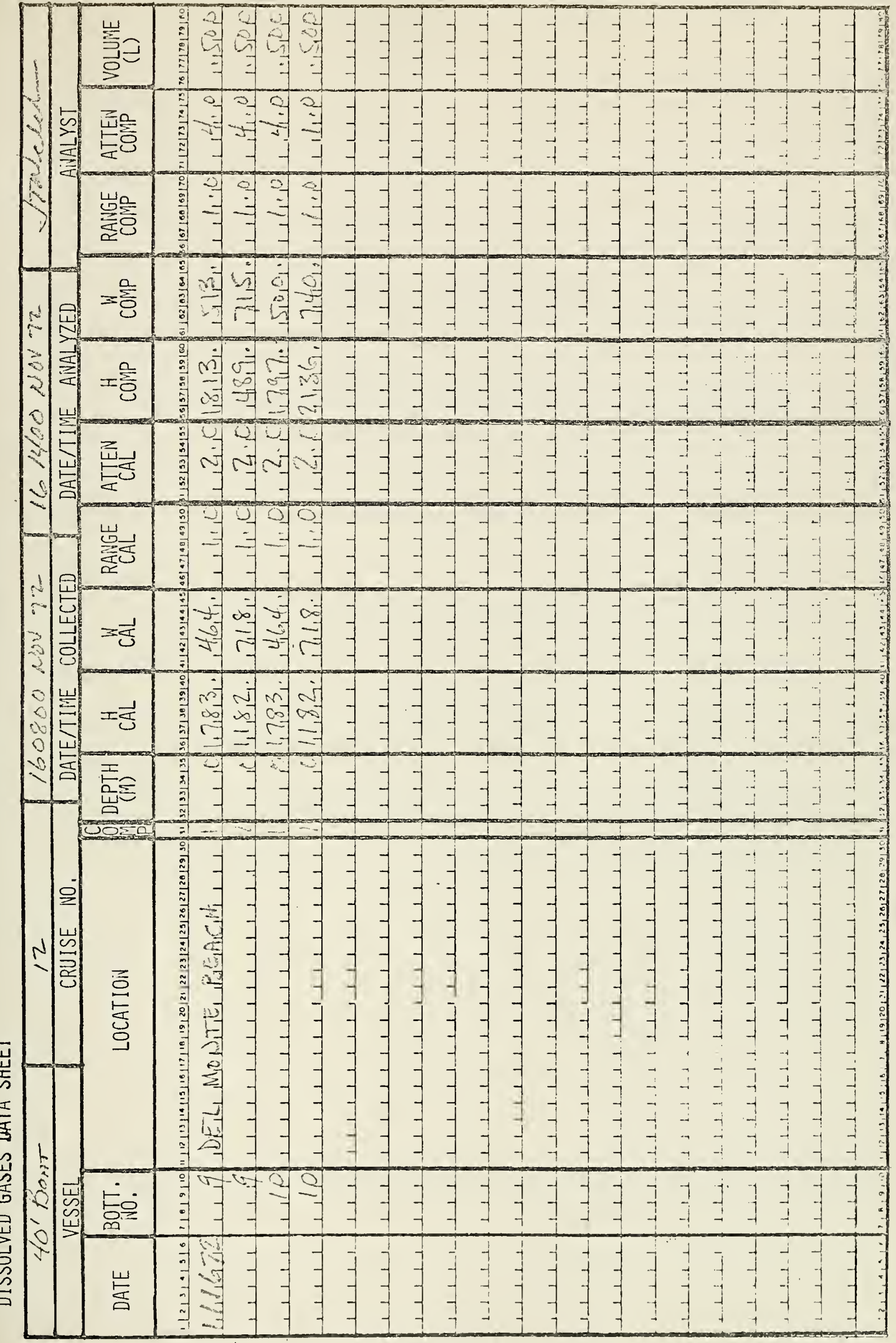







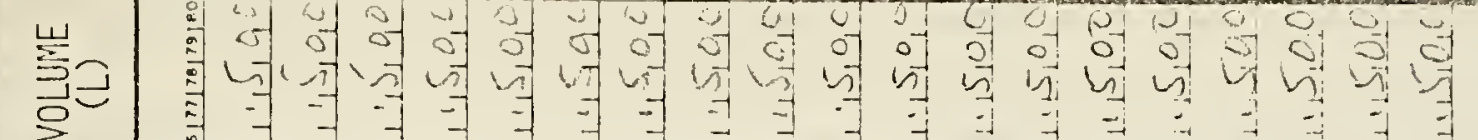

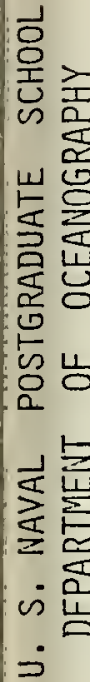

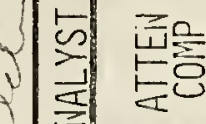

0
-3

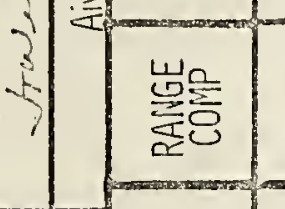

$=-1$

虫 $=\sum^{\circ}$

6.

बी

$\Rightarrow$

-

Sु)

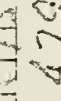

trat

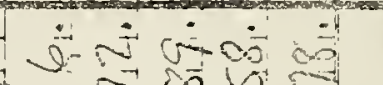

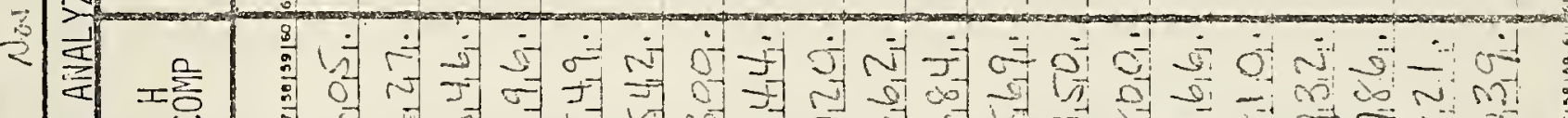

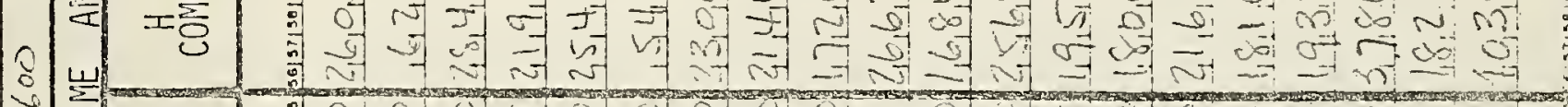

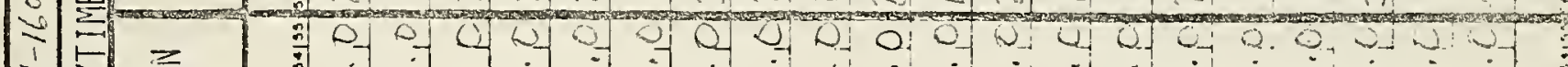

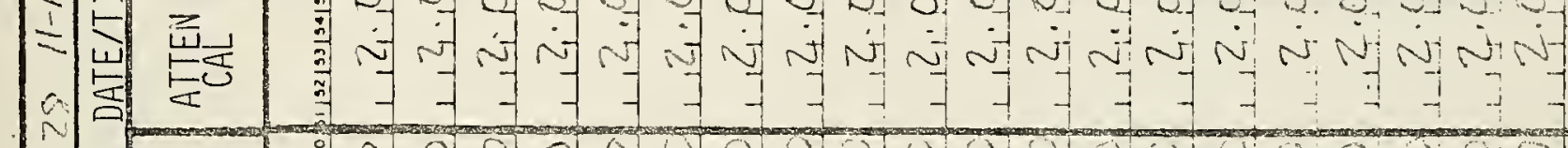

\begin{tabular}{lll}
\hline & 0
\end{tabular}

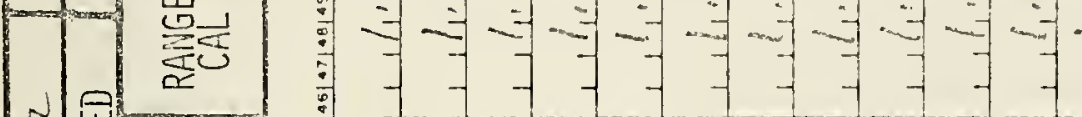

$\sqrt{1}$

$=\frac{1}{v}$

जी :

岸

工霍

O)

of it

it

जी

is 1

(1)

जf

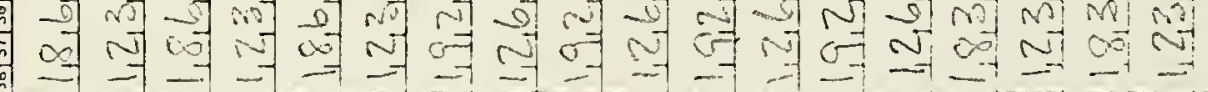

$\sim 2$ 互

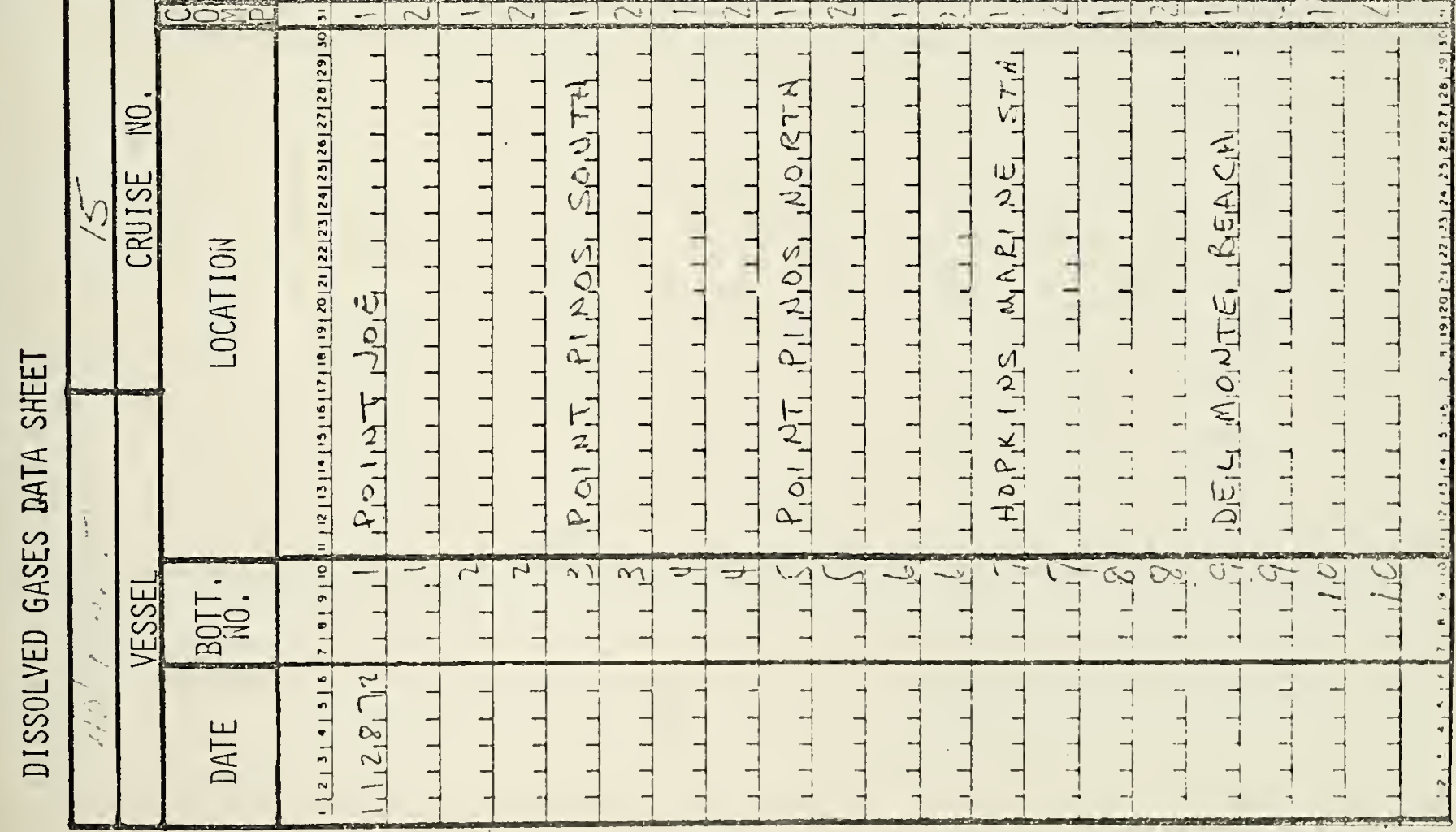







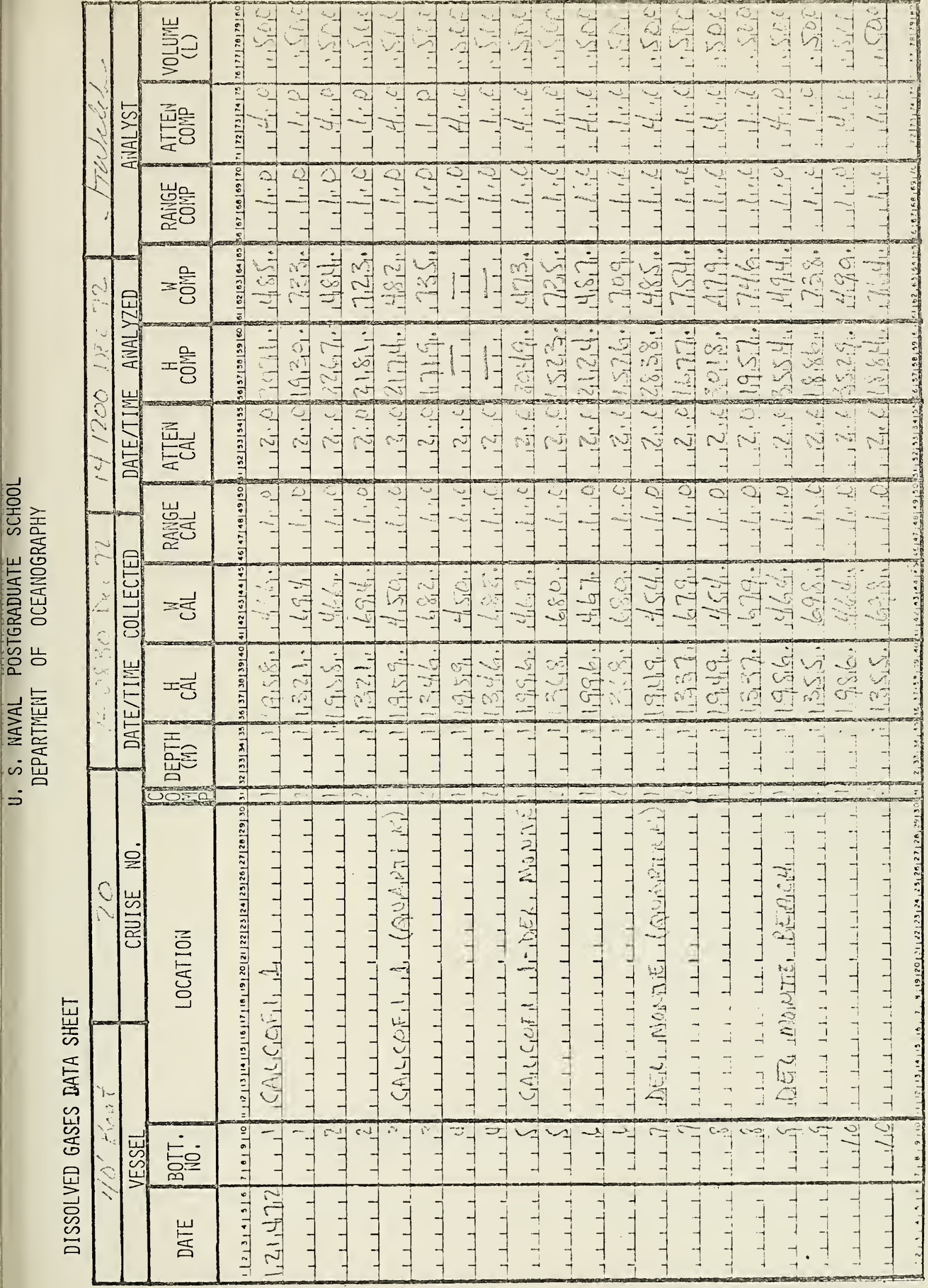







\section{w}

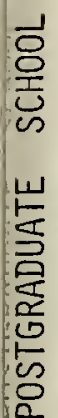

至 至言

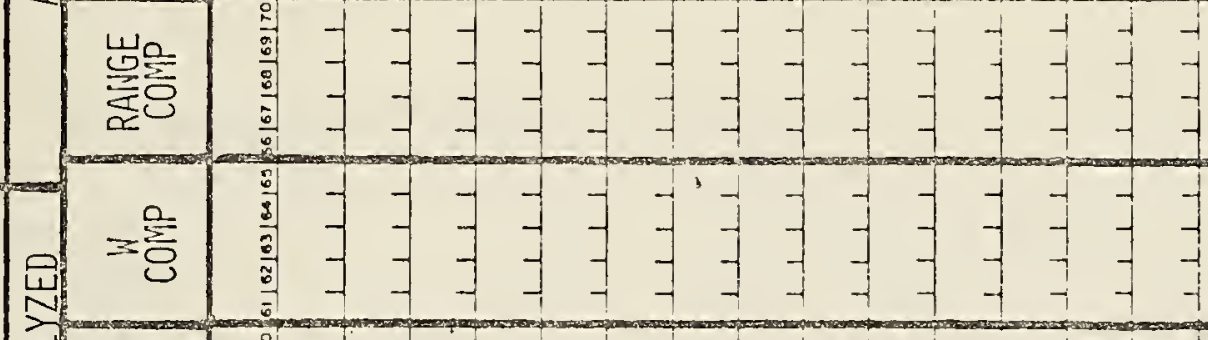

政

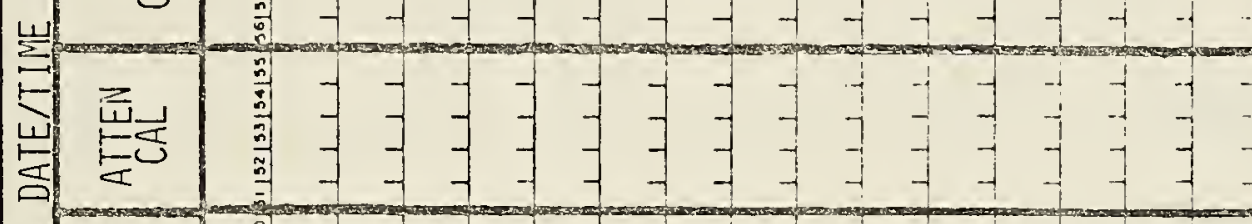

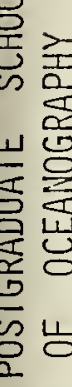

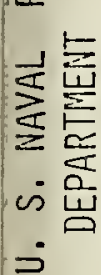

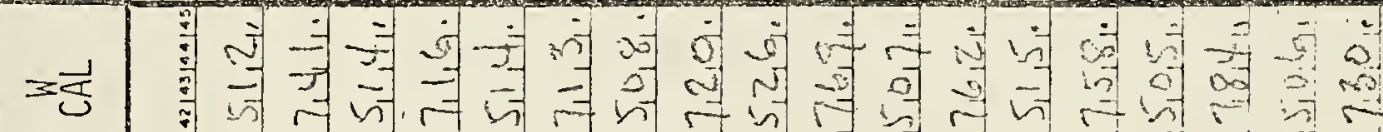

嵌它

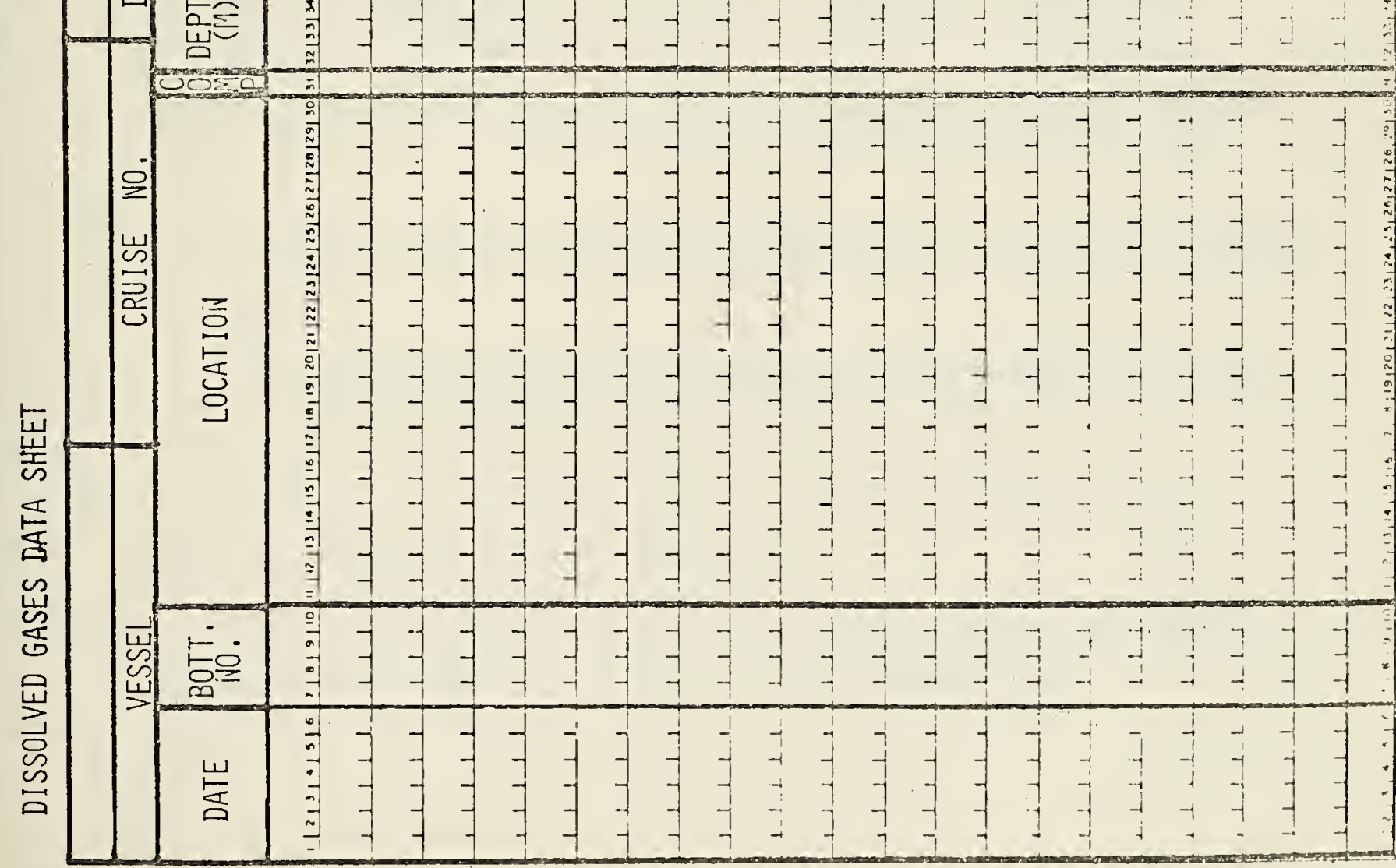



Barham, E. G., "Siphonophores and the Deep Scattering Layer," Science, v. 140 (3568), p. 826-828, May 1963.

Chapman, D. J., and R. D. Tocher, "Occurrence and Production of Carbon Monoxide in Some Brown Algae," Can. J. Bot., v. 44, p. 1438-1442, 1966.

Delwiche, C. C., "Carbon Monoxide Production and Utilization by Higher Plants," Ann. N. Y. Acad. Sci., v. 174, p. 116, 1970.

Jaffe, L. S., "The Global Balance of Carbon Monoxide" in, Global Effects of Environmental Pollution, 1968, S.F. Singer, ed., Springer-Verlag, p. 34-49, 1970 .

Junge, C., W. Seiler, R. Bock, K. D. Greese, and F. Radler, "Uber die CO-Produktion von Mikroorganismer. "Naturwissenschaften, v. 58 (7), p. 362-363, 1971 .

Loewus, M. W., and C. C. Delwiche, "Carbon Monoxide Production by Algae," Plant Physiol., v. 38 (4), p. 371-374, July 1963.

Pickwell, G. V., "The physiology of Carbon Monoxide Production by Deep Sea Coelenterates: Causes and Conscquences," Ann. N. Y.Acad. Sci., v. 174, p. 102, 1970 .

Pickwell, G. V., E. G. Barhan, and J. W. Wilton, "Carbon Monoxide Production by a Bathypelagic Siphonophore," Science, v. 144 (1620), p. 860-862, May 1964.

Pine, M. J., "The Methane Fermentations," in, Anaerobic Biological Treatment Processes, F. G. Pohland, American Chemical Society, p. 1-10, 1971.

Porter, K. and D. H. Volman, "Flame Ionization Detection of Carbon Monoxide for Gas Chromatographic Analysis," Anal. Chem., v. 34 (7), p. 748-749, June 1962:

Rowney, J. V., Gradient Analysis of Phytoplankton Productivity and Chemical Parameters in Polluted and Other Nearshore Habitats, Master's Thesis, Naval Postgraduate School, Monterey, California, 1973.

Swinnerton, J.W., V. J. Linnenbom, and C. H. Cheek, "Determination of Dissolved Gases in Aqueous Solutions by Gas Chromatography," Anal. Chem., v. 34 (4) p. 483-485, April 1962.

Swinnerton, J.W., V. J. Linnenbom, and C. H. Cheek, "Revised Sampling Procedure for Determination of Dissolved Gases in Solution by Gas Chromatography," Anal. - Chem., v. 34 (11), p. 1509, October 1962. 

Swinnerton, J. W., V. J. Linnenbom, and C. H. Cheek, "A Sensitive Gas Chromatographic Method for Determining Carbon Monoxide in Sea Water," Limno1. Oceanog., v. 13 (1), p. 193-195, January 1968.

Swinnerton, J. W., V. J. Linnenbon, and C. H. Cheek, "Distribution of Methane and Carbon Monoxide Between the Atmosphere and Natura1 Waters," Env. Sci. Tech., v. 3, p. 836-838, September, 1969.

Swinnerton, J. W., V. J. Linnenbom, and R. A. Lamontagne, "The Ocean: A Natural Source of Carbon Monoxide," Science, v. 167 p. 984-986, February, 1970 .

Wittenberg, J. B., "The Source of Carbon Monoxide in the Float of the Portuguese Man-of-War, Physalia physalis L.," J. Exp. Biol, v. 37 (4), p. 698-705, December 1960 . 

1. Defense Documentation Center Cameron Station

Alexandria, Virginia 22314

2. Library, Code 0212

Naval Postgraduate School

Monterey, California 93940

3. Department of Oceanography Naval Postgraduate School

Monterey, California 93940

4. Oceanographer of the Navy

The Madis on Building

732 North Washington Street

Alexandria, Virginia 22314

5. Dr. Ned Ostenso

Code $480 \mathrm{D}$

Office of Naval Research

Arlington, Virginia 22217

6. Dr. John W. Swinnerton

Chemical Oceanography Branch Ocean Sciences Division

Nava1 Research Laboratory

Washington, D. C. 20390

7. Dr. Eugene D. Traganza

Code $58 \mathrm{Tg}$

Department of Oceanography Naval Postgraduate School

Monterey, California 93940

8. Lieutenant James T. Welch

U. S. Naval Facility NPO 558

Patrick AFB, Florida 32925 

UNCLAS SIFIED

Security Classification

Security classificotion of tillo, body of abstract and indexins ennotation niust be entered when the overall report is classllied

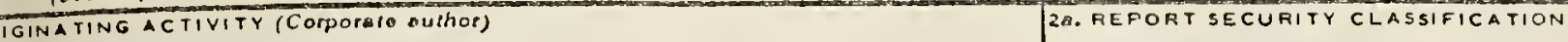

Naval Postgraduate School

Monterey, California 93940

Unclassified 2b. GROUP

EPORT TITLE

Gradient Analysis of Carbon Monoxide and Methane in Polluted and Other Nearshore Habitats

ESCRIPTIVE NOTES (TYPE of report and,inclusive doles)

Master's Thes is (March, 1973). UTHOR(S) (First nemo, middle inillol, lest namo)

James Taylor Welch

\begin{tabular}{|c|c|c|}
\hline $\begin{array}{l}\text { EPOAT OATE } \\
\text { March } 1973 \\
\end{array}$ & $\begin{array}{r}\text { 7A. TOTAL NO. OF PAGES } \\
84\end{array}$ & $\begin{array}{r}\text { 76. NO. OF REFS } \\
17\end{array}$ \\
\hline $\begin{array}{l}\text { CONTFACT OR GRANT NO. } \\
\text { PROJECT NO. }\end{array}$ & \multicolumn{2}{|c|}{ QA. ORIGINATOF'S REPORT NUMEER(S) } \\
\hline . & $\begin{array}{l}\text { ob. OTREF REPOAT NO(S) } \\
\text { (his ESPOP() }\end{array}$ & thar numbere that may bo noelgned \\
\hline
\end{tabular}

DISTRIBUTION STATEMENT

Approved for public release; distribution unlimited.

SUPPLEMENTARY NOTES

PONSOFING MILITARY ACTIVITY

Naval Postgraduate School

Monterey, California 93940

ABSTRACT

A system for the determination of dissolved gases in seawater by gas chromatography was constructed and used to find the concentrations of methane and carbon monoxide in a variety of habitats around the Monterey Peninsula. Methane was shown to have a maximum of $2.8 \times 10^{-4} \mathrm{~m} 1 / 1$ at 50 meters at the open ocean station, with a surface value of $1.1 \times 10^{-4} \mathrm{ml} / 1$. The surface waters at the nearshore stations were almost three times this value. Methane was also shown to be an effective tracer for sewage effluent. The carbon monoxide maximum of $2.1 \times 10^{-4} \mathrm{ml} / 1$ was found at 15 meters which correlated closely with primary productivity (Rowney 1973). The surface values of $0.81 \times 10^{-4} \mathrm{ml} / 1$ was lower than the nearshore values. All stations sampled were found to be highly supersaturated with both gases. This indicates that in this area, the ocean is a major source of both methane and carbon monoxide. 

UNCLASSIFIED

Security Classification

KEY WOROS

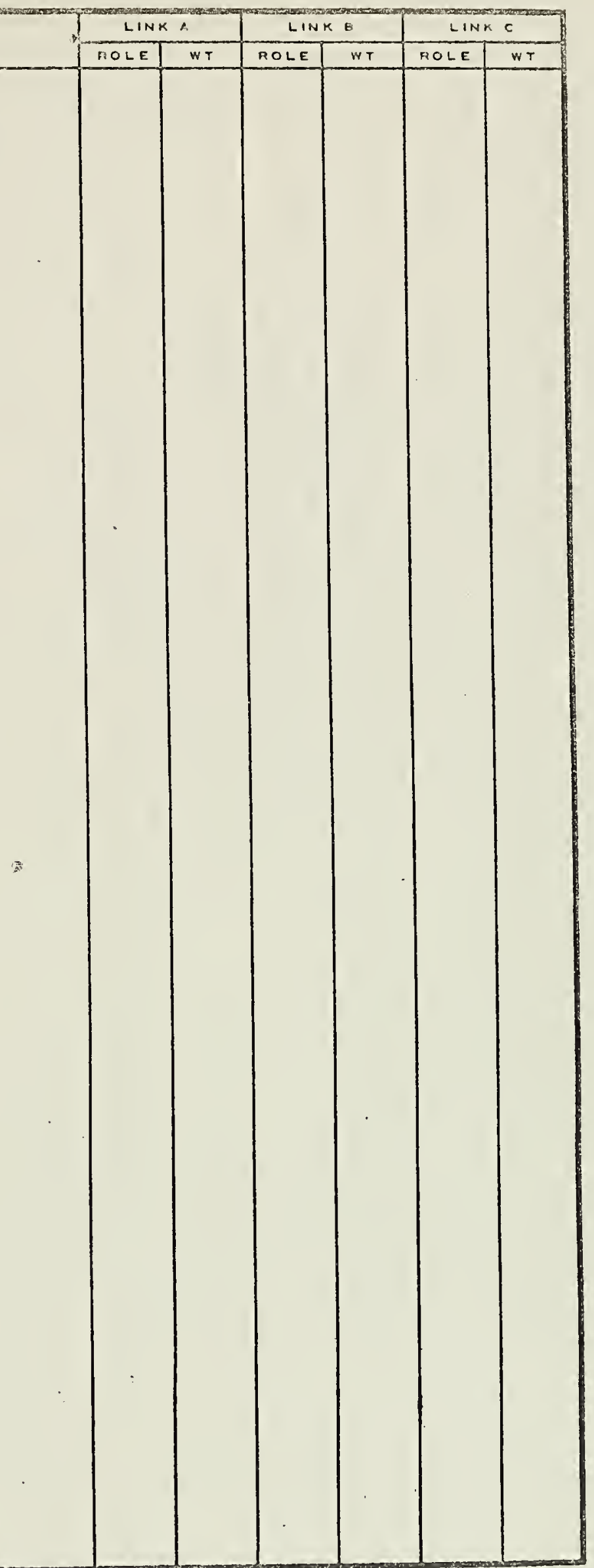

gas chromatography

methane

carbon monoxide

dissolved gases

gradient analysis

gas analysis

seawater analysis

pollution 



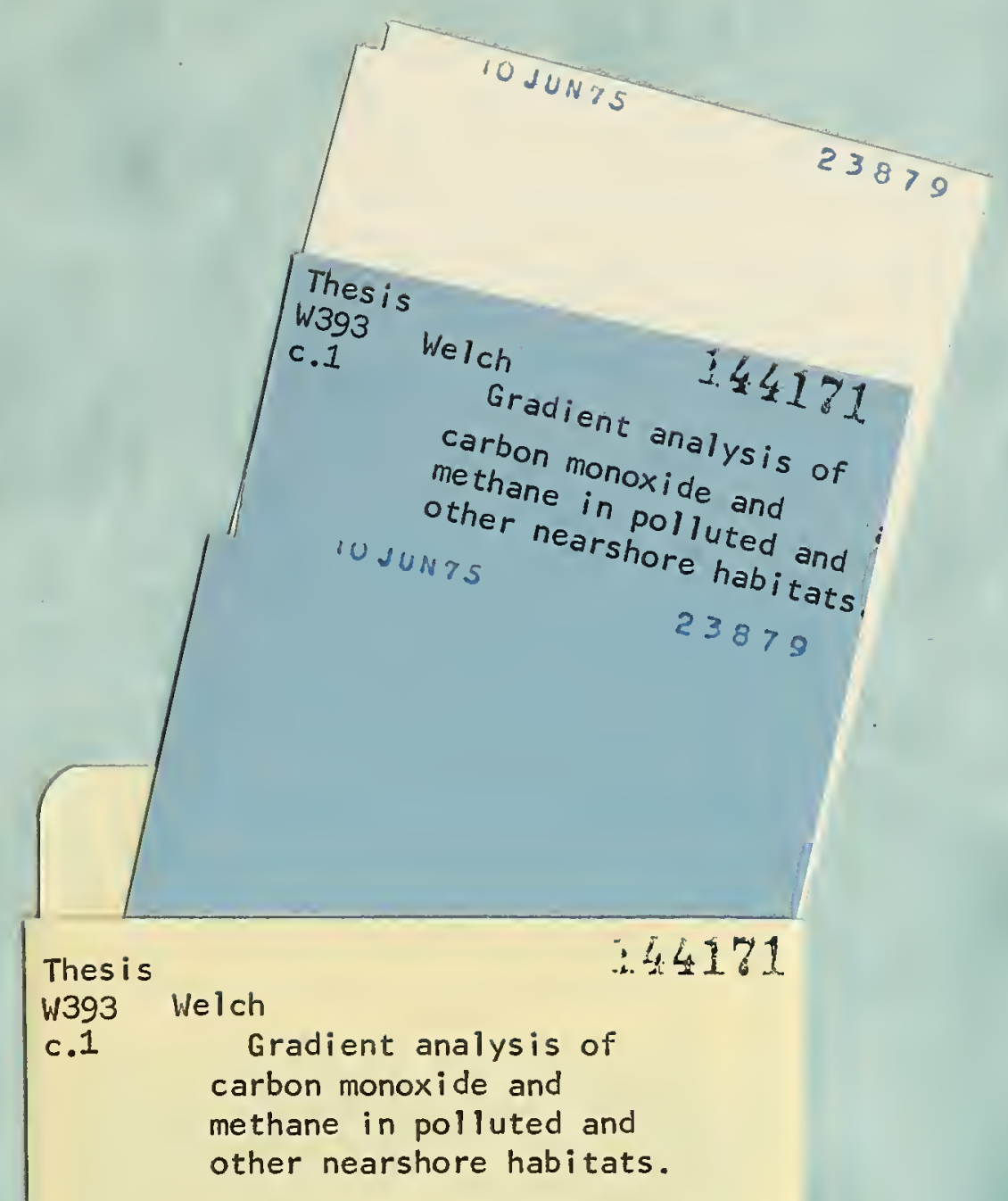


Gradient analysis of carbon monoxide and Gradient analysis of carbon mo HW HW HW

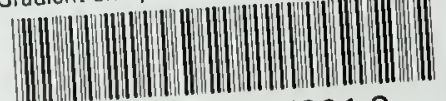

32768001952013

DUDLEY KNOX LIBRARY 